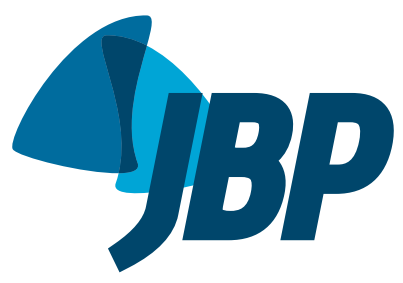

\title{
Brazilian consensus on non-cystic fibrosis bronchiectasis
}

\author{
Mônica Corso Pereira',a, Rodrigo Abensur Athanazio ${ }^{2, b}$, \\ Paulo de Tarso Roth Dalcin ${ }^{3,4, c}$, Mara Rúbia Fernandes de Figueiredo ${ }^{5, \mathrm{~d}}$, \\ Mauro Gomes ${ }^{6,7, \mathrm{e}}$, Clarice Guimarães de Freitas ${ }^{8, f}$, Fernando Ludgren ${ }^{9, \mathrm{~g}}$, \\ Ilma Aparecida Paschoal ${ }^{1, \mathrm{~h}}$, Samia Zahi Rached ${ }^{2, \mathrm{i}}$, Rosemeri Maurici ${ }^{10, \mathrm{j}}$
}

1. Departamento de Clínica Médica, Faculdade de Ciências Médicas, Universidade Estadual de Campinas UNICAMP - Campinas (SP) Brasil.

2. Divisão de Pneumologia, Instituto do Coração - InCor - Faculdade de Medicina, Universidade de São Paulo, São Paulo (SP) Brasil.

3. Departamento de Medicina Interna, Universidade Federal do Rio Grande do Sul, Porto Alegre (RS) Brasil.

4. Serviço de Pneumologia, Hospital de Clínicas de Porto Alegre Porto Alegre (RS) Brasil.

5. Hospital de Messejana Dr. Carlos Alberto Studart Gomes, Fortaleza (CE) Brasil.

6. Faculdade de Ciências Médicas da Santa Casa de São Paulo, São Paulo (SP) Brasil.

7. Equipe de Pneumologia, Hospital Samaritano, São Paulo (SP) Brasil.

8. Unidade de Pneumologia, Instituto Hospital de Base do Distrito Federal, Brasília (DF) Brasil.

9. Hospital Otavio de Freitas, Recife (PE) Brasil.

10. Programa de Pós-Graduação em Ciências Médicas, Universidade Federal de Santa Catarina, Florianópolis (SC) Brasil.

a. (ID) http://orcid.org/0000-0002-7669-4841

b. (D) http://orcid.org/0000-0002-9399-5275

c. (D) http://orcid.org/0000-0002-9774-9135

d. (ID) http://orcid.org/0000-0001-8711-8957

e. (ID) http://orcid.org/0000-0002-5165-4501

f. (D) http://orcid.org/0000-0002-1060-782

g. (D) http://orcid.org/0000-0003-2188-4282

h. (D) http://orcid.org/0000-0002-0539-4243

i. (D) http://orcid.org/0000-0001-6741-1320

j. (ID) http://orcid.org/0000-0001-9627-2112

Submitted: 15 April 2019.

Accepted: 16 May 2019.

Study carried out in the Departamento de Clínica Médica, Faculdade de Ciências Médicas, Universidade Estadual de Campinas - UNICAMP - Campinas (SP) Brasil.

\begin{abstract}
Bronchiectasis is a condition that has been increasingly diagnosed by chest HRCT. In the literature, bronchiectasis is divided into bronchiectasis secondary to cystic fibrosis and bronchiectasis not associated with cystic fibrosis, which is termed non-cystic fibrosis bronchiectasis. Many causes can lead to the development of bronchiectasis, and patients usually have chronic airway symptoms, recurrent infections, and CT abnormalities consistent with the condition. The first international guideline on the diagnosis and treatment of non-cystic fibrosis bronchiectasis was published in 2010. In Brazil, this is the first review document aimed at systematizing the knowledge that has been accumulated on the subject to date. Because there is insufficient evidence on which to base recommendations for various treatment topics, here the decision was made to prepare an expert consensus document. The Brazilian Thoracic Association Committee on Respiratory Infections summoned 10 pulmonologists with expertise in bronchiectasis in Brazil to conduct a critical assessment of the available scientific evidence and international guidelines, as well as to identify aspects that are relevant to the understanding of the heterogeneity of bronchiectasis and to its diagnostic and therapeutic management. Five broad topics were established (pathophysiology, diagnosis, monitoring of stable patients, treatment of stable patients, and management of exacerbations). After this subdivision, the topics were distributed among the authors, who conducted a nonsystematic review of the literature, giving priority to major publications in the specific areas, including original articles, review articles, and systematic reviews. The authors reviewed and commented on all topics, producing a single final document that was approved by consensus.
\end{abstract}

Keywords: Bronchiectasis; Tomography, X-ray; Radiography, thoracic

\section{INTRODUCTION}

\section{Socioeconomic impact of bronchiectasis}

Once considered an orphan disease, ${ }^{(1)}$ permanent airway dilatation, known as bronchiectasis, is a condition that is more common than previously thought. The widespread use of chest HRCT is probably the major factor in the increased diagnosis of bronchiectasis, since it contributes greatly to the detection and better visualization of dilated bronchi and other bronchial and bronchiolar abnormalities. Other important factors in the increased diagnosis of bronchiectasis are the aging of the population, the increased rates of other pathological conditions that can be associated with the development of bronchiectasis, and more widespread diagnostic suspicion.

Data from the Brazilian National Ministry of Health show that, in Brazil, the rate of hospitalization for chronic respiratory diseases decreased from $434.4 / 100,000$ population in 2003 to $241.8 / 100,000$ population in 2013 . Of the latter total, $54.5 \%$ were due to obstructive diseases and only $0.37 \%(0.9 / 100,000$ population $)$ were due to bronchiectasis. As regards the mortality rate in 2013, although obstructive diseases accounted for $64 \%$ of all deaths from chronic respiratory diseases $(33.6 / 100,000$ population), bronchiectasis resulted in a mortality rate of $0.2 / 100,000$ population.(2) It should be emphasized here that these national data may be underestimated because they are based exclusively on hospital inpatient information.

Global epidemiological data shows that the diagnosis of bronchiectasis has increased, with disease prevalence increasing with age and varying geographically

Correspondence to:

Mônica Corso Pereira. Departamento de Clínica Médica, Faculdade de Ciências Médicas, Universidade Estadual de Campinas, Rua Tessália Vieira de Camargo,

126. Cidade Universitária Zeferino Vaz, CEP 13083-887, Campinas, SP, Brasil.

Tel.: 55 19 3521-8281. E-mail: moncorso@gmail.com

Financial support: None. 
and ethnically. ${ }^{(3)}$ In the USA, an annual increase of $8.7 \%$ has been reported for the $2000-2007$ period, ${ }^{(4)}$ as has a similar increase among women and the elderly between 2009 and 2013. ${ }^{(5)}$ In the United Kingdom, the incidence and prevalence rates of bronchiectasis have increased annually since 2004 and are associated with significant mortality. ${ }^{(6)}$ Recent estimates indicate a prevalence rate of 1 in every 206 men and 1 in every 176 women in the United Kingdom; 1 in every 276 people in Spain; and 1 in every 1,492 people in Germany. ${ }^{(6-8)}$ These numbers may be underestimated if we consider the fact that COPD patients can present with bronchiectasis on HRCT at rates ranging from $29-50 \%$ in different publications. ${ }^{(9-11)}$

The socioeconomic impact of bronchiectasis has been more fully studied in recent years. In the USA, a pharmacoeconomic study based on a large database showed that the average increase in overall health costs after the first year of diagnosis of bronchiectasis, compared with controls, was US $\$ 2,319.00$. $^{(12)}$

Treatment costs increase with disease severity and with factors such as age, chronic Pseudomonas aeruginosa infection, exacerbations, and hospital admissions. ${ }^{(13)}$ In a study conducted in Spain, the mean annual cost per patient with bronchiectasis was $€ 4,671.00$, and this value doubled with each increase in severity (as determined by the FACED score $^{1}$ ). In patients with mild disease, the costs were mainly due to the use of bronchodilators and inhaled corticosteroids, and, in those with severe disease, they were mainly due to exacerbations and the use of inhaled antibiotics. ${ }^{(13)}$ The therapeutic management of some subgroups of patients, such as individuals with COPD, also consumes more financial resources.

These findings underscore the importance of diagnosis and appropriate management of bronchiectasis patients. In addition, preventing exacerbations should be a goal not only to improve quality of life and preserve lung function but also to reduce the economic costs associated with bronchiectasis. ${ }^{(14,15)}$

\section{Referral centers/multidisciplinary care}

In Brazil, a survey conducted by the Committee on Respiratory Infections and Pulmonary Mycoses of the Sociedade Brasileira de Pneumologia e Tisiologia (SBPT, Brazilian Thoracic Association) showed that, in 2012, most bronchiectasis patients were treated in general outpatient clinics (66\%). Only $22 \%$ were treated in specialized bronchiectasis outpatient clinics, and the remaining $12 \%$ were treated in integrated outpatient clinics combining pulmonology and cystic fibrosis care (Figure 1; unpublished data).

Given the complexity of the etiologic diagnosis of bronchiectasis and the multisystem nature of this condition, there is a need for multidisciplinary management, preferably performed in centers with experience in the care of bronchiectasis patients.

1 FACED: acronym for FEV $_{1}$, Age, Chronic colonization with Pseudomonas aeruginosa, Extent (of CT findings), and Dyspnea.
The improvement in the survival of cystic fibrosis patients is one example of the benefits of this type of approach. In addition to early diagnosis and access to medications, multidisciplinary care at a referral center is a determinant of disease course in cystic fibrosis patients. ${ }^{(16)}$

A referral center for non-cystic fibrosis bronchiectasis should have resources to carry out a careful etiologic investigation that will enable the establishment of the correct diagnosis, as well as expertise for the pharmacological and non-pharmacological management of various levels of severity. The multidisciplinary team should include physicians (pulmonologists and chest surgeons), nurses, physical therapy professionals, pharmacists, nutritionists, and social workers. In addition, it should be associated with qualified pulmonary function and microbiology laboratories and have access to pulmonary rehabilitation programs. ${ }^{(17,18)}$

\section{METHODOLOGY}

The SBPT Committee on Respiratory Infections summoned 10 pulmonologists with expertise in bronchiectasis in Brazil to conduct a critical assessment of the available scientific evidence and international guidelines, as well as to identify aspects that are relevant to the understanding of the heterogeneity of the clinical presentation of bronchiectasis and its diagnostic and therapeutic management. Five broad topics were established (pathophysiology, diagnosis, monitoring of stable patients, treatment of stable patients, and management of exacerbations). After this subdivision, the topics were distributed among the authors, who conducted a nonsystematic review of the literature, giving priority to major publications in the specific areas, including original articles, review articles, and systematic reviews. All authors had the opportunity to review and comment on all topics, producing a single final document that was approved by consensus.

\section{DEFINITION AND PATHOPHYSIOLOGY}

The term bronchiectasis refers to evidence of irreversible bronchial dilatation, usually found on chest CT scans. There are many congenital and acquired conditions related to the onset of bronchiectasis (Chart 1). ${ }^{(19)}$ The most widely accepted hypothesis to explain the onset of bronchiectasis is the one that proposes an interaction, at different levels of intensity, between an environmental insult and an individual with congenitally susceptible lungs. Increased susceptibility is an impairment of pulmonary defense mechanisms, such as mucociliary transport and availability of IgG and antiproteases in the distal air spaces. ${ }^{(20)}$

Impaired defense mechanisms make the elimination of inhaled biological and non-biological particles and toxic gases less efficient. These agents remain in both the proximal and distal airways. Retained bacteria and viruses proliferate within the airways, change the composition of the normal lung microbiome, and 
trigger inflammation. Prolonged inflammation causes pulmonary structural damage and further impairs the mechanisms of airway clearance. Thus, the well-known vicious cycle implicated in the pathophysiology of bronchiectasis is initiated (Figure 1). ${ }^{(20)}$

A characteristic common to several conditions associated with the onset of bronchiectasis is the concomitant lesion of the small and large airways. This has been demonstrated in chronic bronchitis of COPD and in cystic fibrosis. ${ }^{(21,22)}$ Nonspecific inflammatory processes of the small airways (bronchiolitis and bronchiolectasis) may even precede disease onset.

The condition that triggers the vicious cycle described above cannot always be identified. In such cases, patients have a presumptive diagnosis of idiopathic bronchiectasis. Although pulmonary involvement in bronchiectasis is usually diffuse and bilateral, in rare cases, bronchial obstruction may lead to localized bronchial dilatation because it prevents the proper functioning of mucociliary transport.

Chief among the conditions that affect the lungs diffusely are some viral infections (adenovirus; measles) (23-25) and bacterial infections (pertussis; bacterial pneumonias), ${ }^{(26)}$ all of which can act as triggers for the development of bronchiectasis. In Brazil, pulmonary tuberculosis is also of note because it is a disease that has high incidence and prevalence ${ }^{(27)}$ and leaves lung sequelae in the form of different size areas of chronic bronchial dilatation. ${ }^{(28)}$

Conditions that directly affect airway clearance, such as ciliary dyskinesia and cystic fibrosis, can also be triggers of events leading to diffuse bronchiectasis. Ciliary dyskinesia impairs the functioning of the ciliary apparatus and leads to accumulation of secretions, especially in the small airways. ${ }^{(29)}$ Cystic fibrosis, whose genetic defect results in thicker, harder to clear secretions, shows a trend toward accumulation of these secretions in the small airways and an increased risk of bacterial contamination. ${ }^{(16,22)}$

The design of the airways, similar to a tree, in which new branches grow dichotomously, allows the identification of bronchial generations. From the trachea to approximately bronchial generation 6, air is transported by convection (pressure gradient) and there is airflow. As the cross-sectional area progressively increases with every new airway generation, the airflow progressively decreases until, at around bronchial generation 15, there is no airflow and the gas molecules move by diffusion. ${ }^{(30)}$ From this

Chart 1. Causes and conditions associated with bronchiectasis.

\begin{tabular}{|c|c|c|}
\hline \multirow{7}{*}{$\begin{array}{l}\text { Congenital } \\
\text { conditions }\end{array}$} & \multicolumn{2}{|l|}{ Cystic fibrosis ${ }^{\mathrm{a}}$} \\
\hline & \multicolumn{2}{|l|}{ Alpha-1 antitrypsin deficiency ${ }^{\mathrm{a}}$} \\
\hline & \multicolumn{2}{|l|}{ Primary ciliary dyskinesia ${ }^{a}$} \\
\hline & \multicolumn{2}{|l|}{ Young's syndrome } \\
\hline & \multicolumn{2}{|c|}{ Primary ((humoral, cellular, or combined) immunodeficiencies ${ }^{a}$} \\
\hline & \multicolumn{2}{|c|}{$\begin{array}{l}\text { Anatomical defects in the tracheobronchial tree (tracheobronchomalacia [Williams-Campbell } \\
\text { syndrome], tracheobronchomegaly [Mounier-Kuhn syndrome]) }\end{array}$} \\
\hline & \multicolumn{2}{|l|}{ Pulmonary sequestration } \\
\hline \multirow[t]{15}{*}{ Acquired conditions } & \multirow[t]{5}{*}{ Post-infectious } & Tuberculosis, nontuberculous mycobacterial infections \\
\hline & & Fungal infections (e.g., Paracoccidioides brasiliensis) \\
\hline & & Viral infections (adenovirus, measles virus) \\
\hline & & Swyer-James-MacLeod's syndrome \\
\hline & & Bacterial diseases (Staphylococcus aureus, other bacteria) \\
\hline & $\begin{array}{l}\text { Chronic obstructive respiratory } \\
\text { diseases }\end{array}$ & COPD, bronchial asthma \\
\hline & Secondary immunodeficiencies & $\begin{array}{l}\text { HIV, neoplasms, treatment with immunosuppressants or } \\
\text { biological agents }\end{array}$ \\
\hline & \multirow[t]{2}{*}{$\begin{array}{l}\text { Systemic diseases (autoimmune } \\
\text { mechanisms) }\end{array}$} & $\begin{array}{l}\text { Rheumatoid arthritis, Sjögren's syndrome, systemic lupus } \\
\text { erythematosus }\end{array}$ \\
\hline & & $\begin{array}{l}\text { Inflammatory bowel disease (Chron's disease, ulcerative } \\
\text { colitis) }\end{array}$ \\
\hline & Hypersensitivity-mediated & Allergic bronchopulmonary aspergillosis \\
\hline & $\begin{array}{l}\text { Secondary to inflammatory } \\
\text { pneumonitis }\end{array}$ & $\begin{array}{l}\text { Gastroesophageal reflux disease, chronic microaspiration, } \\
\text { radiotherapy, inhalation of gases or other toxic agents }\end{array}$ \\
\hline & \multirow[t]{2}{*}{ Localized (obstructive) processes } & Intrabronchial (benign tumors, foreign body aspiration) \\
\hline & & Extrabronchial (lymph node enlargement, tumors) \\
\hline & Post-transplant (immune-mediated) & $\begin{array}{l}\text { Host-versus-graft reaction (bone marrow transplantation, } \\
\text { lung transplantation) }\end{array}$ \\
\hline & Other (rare) conditions & $\begin{array}{l}\text { Yellow nail syndrome, sarcoidosis, endometriosis, } \\
\text { amyloidosis, diffuse panbronchiolitis }\end{array}$ \\
\hline & nknown cause) & \\
\hline
\end{tabular}

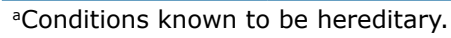


Pneumonias

Tuberculosis

Nontuberculous mycobacterial infection

Immunodeficiency predisposing to infections
Allergic bronchopulmonary aspergillosis Connective tissue diseases Inflammatory bowel diseases Gastroesophageal reflux disease (chronic microaspiration)

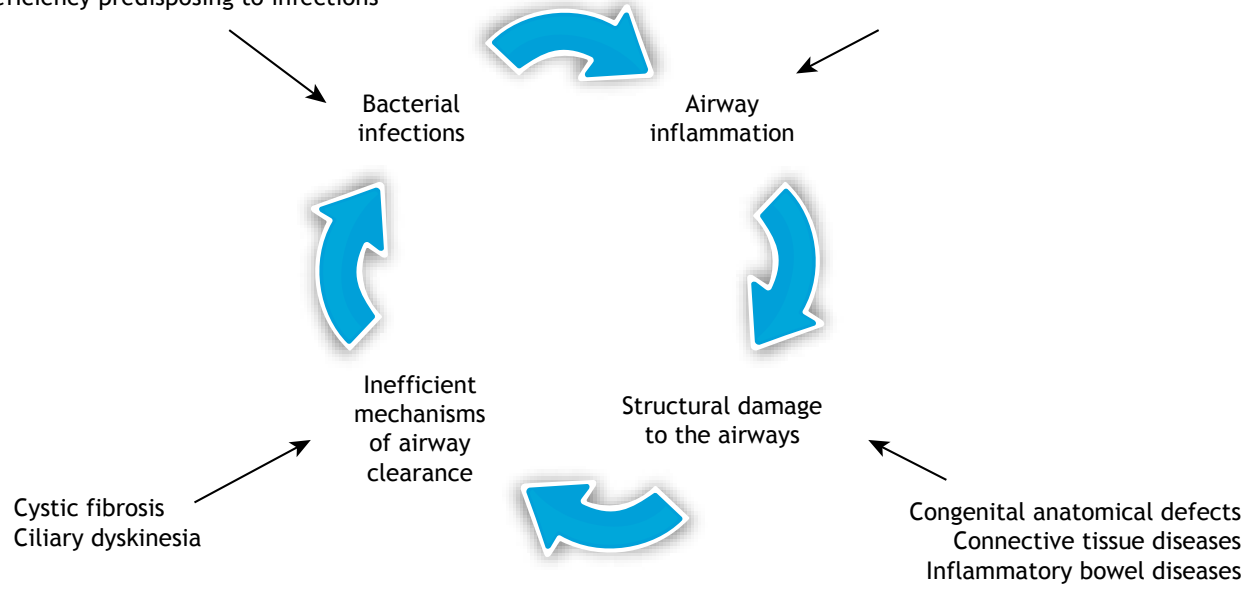

Figure 1. Pathophysiology of bronchiectasis: a "vicious cycle" of the various factors involved.

airway structure, we can conclude that cough, which is dependent on flow generation, replaces mucociliary transport completely only up to bronchial generation 6 . From generation 7 onward, cough progressively loses its effectiveness, and cough cannot compensate for impaired mucociliary transport from generation 15 onward. ${ }^{(31,32)}$

In cases in which mucociliary transport is ineffective, all inhaled contaminants tend to settle out in the small diameter airways. The incoming bacteria find an environment that is highly conducive to proliferation in that region. The retained chemical and biological agents trigger an inflammatory response that causes more structural damage and further impairs mucociliary transport.

A groundbreaking study by Reid(33) showed, by correlating bronchogram findings and pathology study of surgically resected lobes, that the involvement of large and small airways is often concomitant in bronchiectasis patients. In addition to the lesions in large airways, the author observed small airways whose lumens were partially or totally obstructed by inflammation and/or fibrosis. In many cases, the bronchioles disappeared from their normal position near the pulmonary arteriole and only remains of their structure were found. Depending on the severity of the bronchiolar obliteration, the bronchogram findings included cylindrical bronchiectasis (the least common bronchiolar obliteration), varicose bronchiectasis (the most common obliteration), or cystic/saccular bronchiectasis, in which all small diameter airways were obliterated. This loss of small airways resulted in a much smaller number of bronchial generations being identified. Bronchiectasis therefore appears to be a pattern of bronchial response to various types of injury, which as a rule involve (predominantly neutrophilic) inflammation and in most cases involve chronic airway infections.

\section{DIAGNOSIS}

Diagnosis of bronchiectasis is defined by the presence of (non-reversible) bronchial dilatations on HRCT, which means that this is the imaging modality required and sufficient to confirm or rule out the diagnosis. The causes and associated conditions should then be investigated (Chart 1).

\section{Radiological aspects}

Since its introduction in the 1980s, HRCT has become the gold standard for the diagnosis and evaluation of the extent of airway structural changes. HRCT allows the identification of changes in large diameter airways, such as luminal dilatation and wall thickening. In general, changes in the small airways are also detected and can be described as direct and indirect signs; in some cases, these signs can be eventually seen with no dilatation in central bronchi. Direct signs are the visualization of bronchioles that may be dilated (bronchiolectasis), with their lumen filled with secretion (small, low-density nodules; tree-in-bud pattern) or with thick walls. The tree-in-bud pattern is the visualization of millimetric airway branching, invisible in normal situations, and made possible to be seen by the accumulation of secretion, inflammatory changes, and airway dilatation. ${ }^{(34)}$

The presence of mosaic attenuation, more easily identifiable on TC scan slices obtained during exhalation, is the so-called "indirect sign", which is due to trapping of air in the lobules as a result of subocclusion of the bronchiolar lumen due to bronchiolar wall inflammation/fibrosis. ${ }^{(35)}$ Signs of collapse of lung regions because of recurrent infections may also be seen in some cases. Some of the changes described above can be observed in Figures 2, 3, and 4.

Additional HRCT findings can suggest a specific cause. For example, presence of concomitant emphysema 
is suggestive of COPD, evidence of situs inversus or profusion of nodules suggestive of bronchiolar mucoid impaction in the lower lung fields should lead to ciliary dyskinesia, and evidence of tracheomegaly or pseudodiverticula in the tracheobronchial walls should bring to mind the Mounier-Kuhn syndrome.

The regional distribution of bronchiectasis can provide useful information for the etiologic diagnosis, ${ }^{(36)}$ especially if the bronchiectasis is upper-lobe predominant, a common finding in cystic fibrosis. Predominant involvement of anterior regions (middle lobe and lingula) should lead to nontuberculous mycobacteria(37) or diffuse panbronchiolitis, the latter being classically described in Asians ${ }^{(38)}$ and being rare in Brazil. Predominant involvement of lower lung fields is common to several conditions, such as ciliary dyskinesia ${ }^{(29)}$; conditions associated with chronic aspiration (a cause that should be remembered in patients with an altered mental status); swallowing impairment or gastroesophageal reflux disease( ${ }^{39)}$; bronchiectasis secondary to hypogammaglobulinemia; immunosuppression; and chronic rejection in (lung, bone marrow) transplant recipients. Central predominance with large mucoid impactions (finger-in-glove sign) is suggestive of allergic bronchopulmonary aspergillosis. In cases of bronchiectasis after pulmonary tuberculosis, the distribution of bronchiectasis is often asymmetric, with preferential involvement of upper lobes or apical segments of lower lobes; in addition, pleural thickening and adjacent parenchymal distortion are common. Localized bronchiectasis can be caused by bronchial obstruction, and, in such cases, bronchoscopic investigation is indicated.

\section{Etiologic investigation}

Evidence of bronchiectasis on HRCT is usually obtained during the evaluation of patients with a productive cough and/or recurrent respiratory infections of the upper and lower airways, and may be accompanied or not by chest X-ray abnormalities. For such patients, etiologic investigation after confirmation of the diagnosis by HRCT scan is recommended (Figure 5).
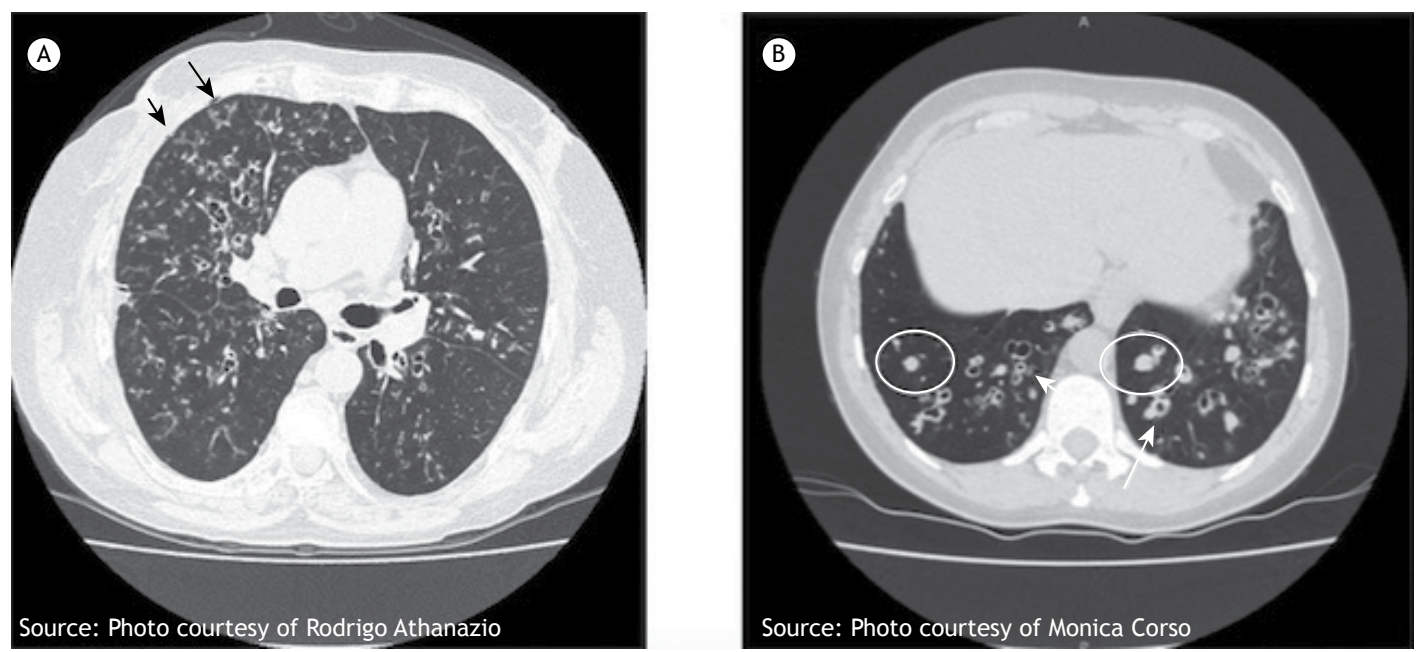

Figure 2. Chest HRCT scan. In A, tree-in-bud pattern (arrows). In B, mucoid impaction (mucus plug) in small airways (circles) and bronchial wall thickening (arrows).
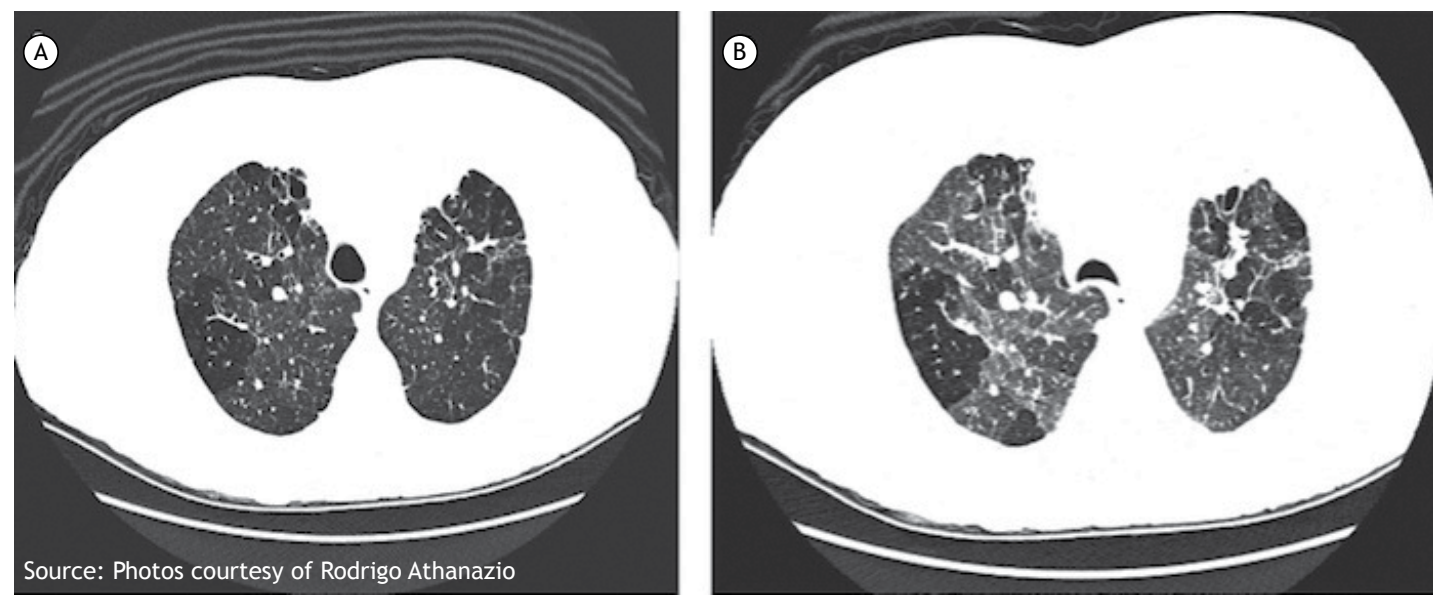

Figure 3. Chest HRCT scan. Mosaic perfusion (or attenuation). Although present in A (inhalation), it is more visible in $B$ (exhalation). The darker areas indicate air trapping due to small airways impairment, associated with oligemia. 

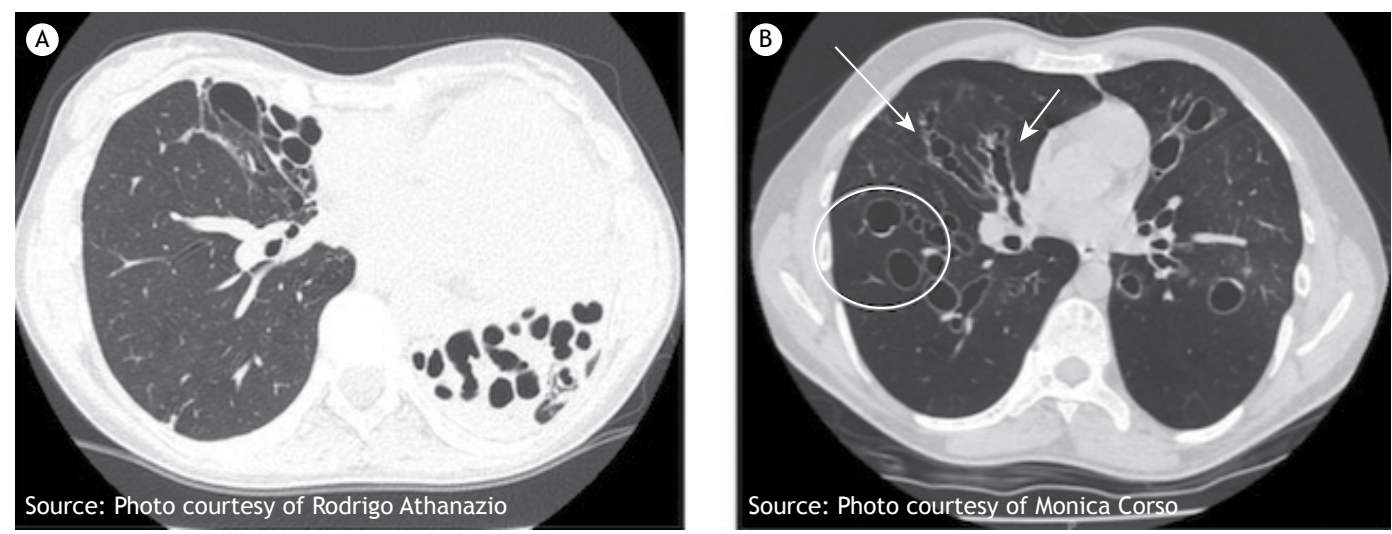

Figure 4. Chest HRCT scan. In A, cystic bronchiectasis in fibroatelectatic areas. In B, varicose bronchiectasis (arrows) and cystic bronchiectasis (circle). Note the loss of bronchial generations (loss of millimetric branching) and impaired visualization of bronchovascular markings, suggestive of air trapping (even during inhalation).

Bronchiectasis may also be detected in patients with respiratory symptoms and with diseases/conditions that occasionally present with airway involvement (COPD, asthma, collagen diseases, inflammatory bowel diseases, cystic fibrosis, and gastroesophageal reflux disease). Even when the cause is known, the possibility of concomitant conditions should be remembered; for example, asthma associated with gastroesophageal reflux disease or allergic bronchopulmonary aspergillosis, and collagen disease associated with infections, such as mycobacterial infection.

The major causes of and major conditions associated with bronchiectasis are listed in Chart 1. In published series, the frequency of each of them may vary according to the region studied (higher prevalence of infections) and the availability of ancillary tests that are necessary for the diagnostic investigation. In most series, post-infectious etiologies are some of the most common, accounting for $20 \%$ to $32 \%$ of cases. $^{(40-42)}$ Bronchiectasis should be considered to be of "unknown cause" (24-40\% of cases) ${ }^{(40,41)}$ only in patients in whom a diagnosis cannot be established even after all recommended tests are performed. In a study ${ }^{(41)}$ that analyzed 1,258 patients from seven databases (Italy, the United Kingdom, Belgium, Spain, Greece, and Ireland), the cause of bronchiectasis was not established in $40 \%$, was post-infective in $20 \%$, was COPD-related in 15\%, was connective tissue disease-related in $15 \%$, was immunodeficiency-related in $5.8 \%$, and was asthma-related in $3.3 \%$.

In the study validating the FACED score, conducted in six centers in Latin America (four of which in Brazil), among the 651 patients enrolled, the cause of bronchiectasis was classified as post-infective in $40.3 \%$; idiopathic in $31.1 \%$; ciliary dyskinesia-related in $9.0 \%$; airway disease-related (COPD, asthma, or bronchiolitis) in 5.1\%; and rheumatic disease-related in $4.3 \% .^{(43)}$

The relevance of etiologic investigation lies in the fact that some conditions may benefit from specific therapeutic measures (allergic bronchopulmonary aspergillosis, collagen diseases, immunodeficiencies, aspiration, ciliary dyskinesia, cystic fibrosis, bronchial obstruction, COPD, and asthma), and this may occur in $13 \%{ }^{(41)}$ to $37 \%{ }^{(42)}$ of cases.

\section{FOLLOW-UP AND MONITORING}

\section{Functional aspects}

All bronchiectasis patients should undergo periodic functional assessment to detect any sign of decreased pulmonary function as early as possible. To that end, spirometry with bronchodilator use is satisfactory in the vast majority of cases. Obstructive lung disease is the most common finding, but significant reductions in FVC can be found in more advanced disease, with increased lung parenchymal destruction. End-expiratory flows are reduced, the RV/TLC ratio is increased (suggesting air trapping), and FVC and TLC are normal or low. $(44,45)$ Decreased $\mathrm{FEV}_{1}$ correlates with the presence of dyspnea-as assessed by the modified Medical Research Council (mMRC) scale-and with the extent of disease on HRCT. ${ }^{(46)}$ Approximately $33 \%$ of bronchiectasis patients have positive methacholine or histamine challenge test results. DLCO test results are usually normal; DLCO may be reduced in advanced disease and in the presence of associated emphysema. ${ }^{(47)}$

The six-minute walk test and the incremental shuttle walk test can provide additional functional information to spirometry. ${ }^{(48,49)}$ The first has the advantage of having been extensively validated in respiratory diseases, and basically requires space and trained personnel in order to be performed. ${ }^{(50)}$ In this context, the six-minute walk distance correlates better with quality of life than with functional tests. ${ }^{(51)}$ The shuttle test can be useful especially in patients with preserved pulmonary function, because of the potential "ceiling effect" of the six-minute walk test, and has been validated for bronchiectasis patients. ${ }^{(49,52)}$

\section{Our recommendation:}

Perform spirometry with bronchodilator use every 6 months, lung volume assessment (if available) annually, and the six-minute walk test (at the physician's discretion). 


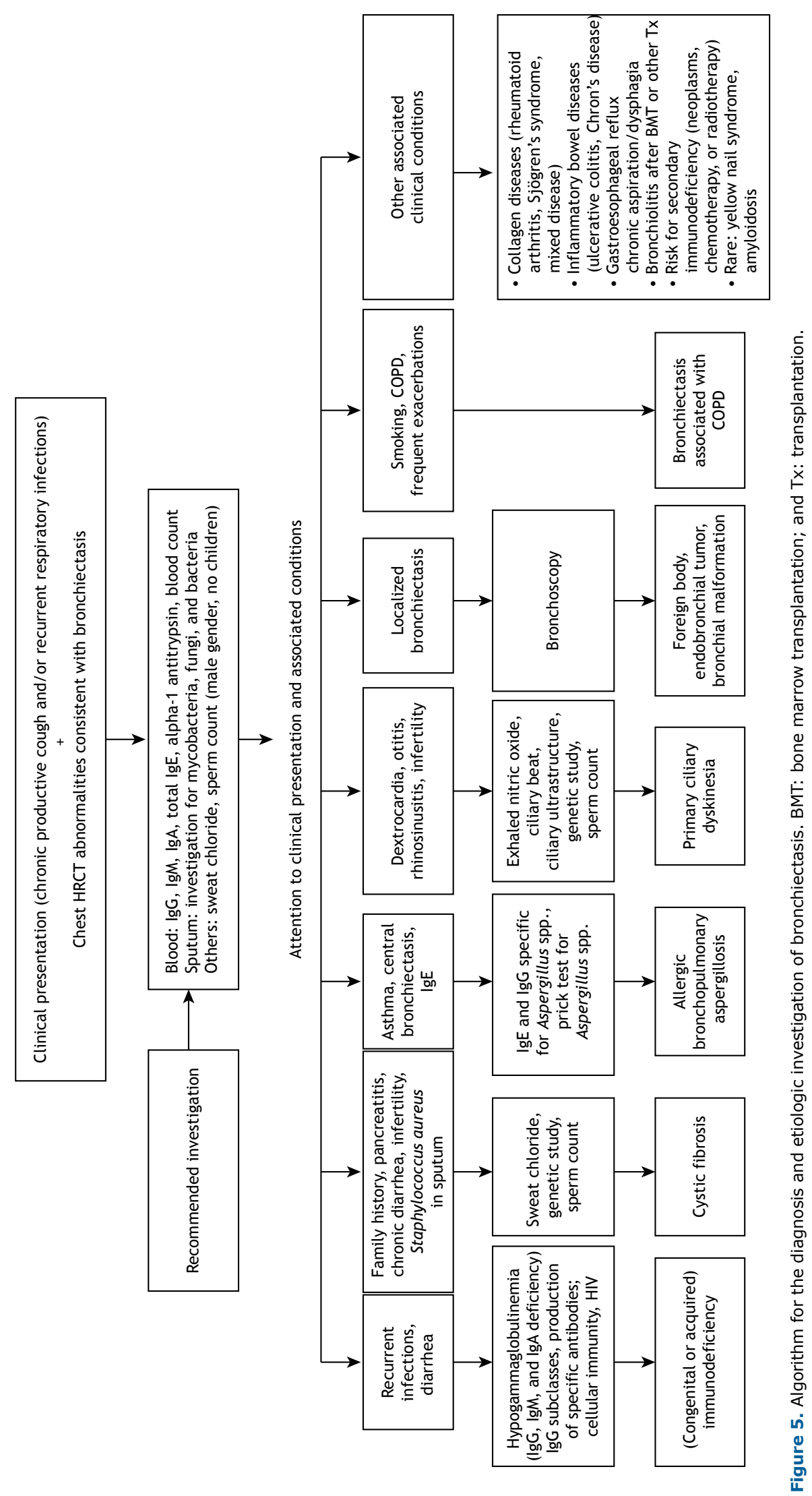




\section{Microbiological aspects}

The identification of potentially pathogenic microorganisms (PPMs) in the airways of bronchiectasis patients is a common finding related to increased bronchial inflammation and, consequently, progressive clinical deterioration. ${ }^{(53)}$ Colonization is understood as the presence, growth, and multiplication of a microorganism in a host without there being any clinical expression or detection of immune response. ${ }^{(54)}$ In this context, the term "bronchial colonization" should be avoided, because the presence of PPMs in the lower airways is not innocuous, and it would therefore be more appropriate to use the term "chronic bronchial infection". There is strong evidence that PPMs are associated with an accelerated decline in pulmonary function, a higher number of exacerbations, worsening of quality of life, and higher mortality. $17,53,55,56)$

PPMs are understood as various species of gramnegative and gram-positive bacteria, mycobacteria, and fungi that have the ability to directly cause lung injury. Recent studies assessing the microbiome have revealed the existence of a great abundance and variety of bacteria in the lower respiratory tract, a finding that is one of the determinants of proper lung functioning and protection against recurrent infections. In bronchiectasis patients, this variety of bacteria is reduced as the proportion of a potentially pathogenic species increases with the severity of the disease. Given the loss of bronchial architecture and the impairment of local defense mechanisms in such patients, there is a greater risk that a PPM will chronically infect their respiratory tract. Chronic bronchial infection may produce changes in the balance of the lung microbiota, and this has a negative impact on the clinical course of the disease. $(57,58)$ The association of a PPM with the sharp decline caused by the disease is well documented in patients with chronic bronchial infection with $P$. aeruginosa. (59) The presence of other bacteria may also cause an accelerated clinical deterioration; however, the real impact of such infections has yet to be fully determined. ${ }^{(60)}$ For example, a recent study using a large American database showed that the identification of methicillin-sensitive Staphylococcus aureus does not appear to be an independent risk factor for severe disease in bronchiectasis patients. ${ }^{(61)}$

Some definitions should be highlighted in this context:

- Primary infection: when a first positive culture for a PPM that was not isolated in previous periodic tests is obtained

- Intermittent bronchial infection: when culture results for a specific PPM are sometimes positive and sometimes negative in samples collected at intervals of at least 1 month after a primary infection

- Chronic bronchial infection: when two or more cultures are positive for the same PPM over a 12 -month period in samples collected at intervals of at least 3 months

- Eradication: when a specific PPM is no longer detected in at least two consecutive samples collected at an interval of at least 1 month over a 6-month period

Sputum is the specimen of choice for culture in order to identify PPMs in bronchiectasis patients. Sputum samples should be immediately delivered to the laboratory or kept under refrigeration for as long as $3 \mathrm{~h}$ after collection. ${ }^{(62)}$ In addition, sputum should be microscopically evaluated to ensure the quality of the sample obtained and its representativeness in terms of the lower respiratory tract, it being necessary that more than 25 leukocytes and less than 10 epithelial cells should be identified per field at a magnification of $\times 100$. In patients who have difficulty expectorating, samples obtained by BAL may be necessary. In such cases, the samples must be quantitatively cultured. ${ }^{(63)}$ When a PPM is identified, antibiotic susceptibility testing is recommended for guiding the choice of systemic antibiotic therapy. However, there is increasing evidence of poor correlation between in vitro susceptibility and in vivo clinical response, especially in the case of biofilm-producing bacteria. ${ }^{(64)}$ Therefore, clinical judgment should guide therapeutic decisions. It is important to emphasize that susceptibility testing is not appropriate for the choice of an inhaled antibiotic. When the inhalation route is used, the drugs reach high concentrations in the lower respiratory tract and their clinical efficacy may remain even in situations of bacterial resistance demonstrated in vitro. ${ }^{(65)}$

\section{Our recommendation:}

Collect samples from the lower respiratory tract (sputum, for example) at regular intervals of 3-4 months and during pulmonary exacerbations for aerobic culture, as well as annually for culture for fungi and mycobacteria. If the patient is being treated with chronic macrolide therapy, culture for mycobacteria should be performed every 6 months.

\section{Quality of life}

Some studies have revealed that bronchiectasis patients have reduced quality of life, fatigue symptoms, and asthenia, as well as high scores on depression and anxiety measures. ${ }^{66,67)}$

Higher levels of depression are associated with greater severity of dyspnea. ${ }^{(68)}$ Patients with chronic bronchial infection with $P$. aeruginosa have poorer quality of life than those with chronic infections with other bacteria. ${ }^{(66)}$ In addition, chronic cough has a negative impact on the quality of life of such patients and their families. ${ }^{(69)}$ However, one group of authors demonstrated that disease severity as measured by CT does not correlate with psychological well-being. ${ }^{(67)}$

\section{Systemic markers}

Inflammatory markers, such as C-reactive protein (CRP) and total leukocyte counts, are related to the extent of disease and to poorer pulmonary function. ${ }^{(70)}$ One study demonstrated that, in stable patients, increased bronchiectasis severity, as assessed by the Bronchiectasis Severity Index (BSI) and the FACED score, correlated with higher CRP levels but not 
with total leukocyte counts or with the neutrophil/ lymphocyte ratio. ${ }^{(71)}$

Airway inflammation has a predominance of neutrophils, which means that some inflammatory cytokines, such as IL-1, IL-6, and TNF-a, are increased, but IL-10 is decreased. ${ }^{(72)}$ However, these cytokines are not markers used in clinical practice.

\section{Our recommendation:}

Although CRP appears to be an inflammation-related marker and is available for use in clinical practice, there is insufficient evidence to recommend its routine use to assess disease severity.

\section{Severity and prognostic scores}

Although there is a clear relationship of increased disease severity and mortality in bronchiectasis patients to chronic $P$. aeruginosa infection, ${ }^{(73)}$ other factors contribute to the clinical and functional course of such patients. Since this is a difficult-to-manage condition, associated with various causes and great clinical heterogeneity, multidimensional scores have been developed in order to better estimate severity and prognosis. The most commonly used are the FACED score ${ }^{(74)}$ and the BSI. ${ }^{(59)}$

The FACED score uses the following variables: $\mathrm{FEV}_{1}$ (\% predicted); age; chronic colonization with $P$. aeruginosa; extent of findings on chest HRCT (number of affected lobes; the lingula is counted as a separate lobe); and dyspnea, as assessed by the mMRC scale.(74) The E-FACED score added severe exacerbation in the previous year to the other variables of the FACED score and was found to be able to predict not only mortality but also the risk of exacerbation. ${ }^{(75)}$ The FACED and the E-FACED scores are user-friendly and have been validated in patients in Brazil (Chart 2). ${ }^{(43)}$ In addition to being useful to predict all-cause mortality and exacerbations, they showed excellent ability to discriminate between different levels of disease severity (from mild to severe). These scores can also be used in order to aid in the assessment of therapeutic response to the adopted interventions. ${ }^{(76)}$

The BSI includes, in addition to the variables of the FACED score, body mass index, chronic infection with microorganisms other than $P$. aeruginosa, hospitalizations, and exacerbations in the previous year. Although completing the BSI is a little more laborious, there is a homepage to that end on the Internet (http://www.bronchiectasisseverity.com/15$2 /)$. The BSI also has good ability to estimate future mortality and exacerbations. ${ }^{(59)}$

\footnotetext{
Our recommendation:

A severity score and a prognostic estimate should be calculated at the time patients are diagnosed with bronchiectasis. Periodic calculation of the score (annually, for example) aids in therapeutic management. To date, the FACED and the E-FACED scores are the ones that have been validated for use in Brazil.
}

\section{THERAPEUTIC MANAGEMENT OF STABLE PATIENTS}

Despite the lack of medications approved by regulatory agencies for the treatment of bronchiectasis patients, various drugs and strategies have shown benefits in improving both quality of life and clinical outcomes. Since bronchiectasis is a complex and heterogeneous disease, treatment should be individualized, considering the peculiarities and clinical manifestations of each patient, and some specific conditions should be treated concurrently. However, some recommendations are important for all bronchiectasis patients, as are some interventions targeted at phenotypes specific to the disease (Figure 6).

\section{Treatment of specific causes or conditions}

Some causes of bronchiectasis have specific treatment or specific therapeutic measures. The detailing of those topics is beyond the scope of the present consensus statement, and there are excellent reviews and some guidelines that may be useful for expanding the knowledge on the topics (Chart 3). . $^{(16,29,77-84)}$

\section{Chronic airway infection}

\section{Primary infection}

There is consensus among experts on the need to attempt eradication in cases of primary $P$. aeruginosa infection. ${ }^{(15,85)}$ Unlike cystic fibrosis, for which $P$. aeruginosa eradication protocols have been adequately established in various clinical trials, ${ }^{(86)}$ evidence is scarce for non-cystic fibrosis bronchiectasis. In the context of cystic fibrosis, $P$. aeruginosa eradication protocols have been simplified to the use of 28-day regimens of inhaled antibiotics alone, with the same rate of efficacy. ${ }^{\left({ }^{(77)}\right)}$ However, most of those interventions occur in the pediatric age group, in patients whose lung architecture is still preserved. In contrast, non-cystic fibrosis bronchiectasis patients commonly present with extensive diffuse pulmonary involvement at the time the primary $P$. aeruginosa infection is identified. We suggest a 14- to 21-day regimen of systemic antibiotic therapy in conjunction with a longer than 3 -month course of inhaled antibiotic therapy. ${ }^{(15,85,88)}$ If the patient is infected with a quinolone-sensitive $P$. aeruginosa strain, we suggest that treatment be started with ciprofloxacin per oral; however, intravenous regimens can be used, such as an antipseudomonal beta-lactam combined with an aminoglycoside. If inhaled antibiotics are unavailable, treatment should consist only of systemic antibiotics. We recommend that follow-up sputum culture be performed 2-4 weeks after treatment completion. If the patient remains culture positive, another protocol can be attempted until a total of three attempts at eradication are made. Thereafter, the patient should be regarded as having chronic bronchial infection. Although the rate of eradication is lower in patients in whom the presence of $P$. aeruginosa mucoid strains is detected, 
Chart 2. E-FACED score: acronym for Exacerbation, $\mathbf{F E V}_{1}$, Age, Chronic colonization with Pseudomonas aeruginosa, Extent (of CT findings), and Dyspnea.

\begin{tabular}{|c|c|c|}
\hline Variables & Result & Score \\
\hline \multirow[t]{2}{*}{ Exacerbation } & No & Zero \\
\hline & Yes & 2 \\
\hline \multirow[t]{2}{*}{$\mathrm{FEV}_{1}, \%$ predicted } & $\geq 50 \%$ & Zero \\
\hline & $<50 \%$ & 2 \\
\hline \multirow[t]{2}{*}{ Age } & $<70$ years & Zero \\
\hline & $\geq 70$ years & 2 \\
\hline \multirow[t]{2}{*}{ Chronic colonization with $P$. aeruginosa } & No & Zero \\
\hline & Yes & 1 \\
\hline \multirow[t]{2}{*}{ Extent of CT findings: number of affected lobes } & $1-2$ lobes & Zero \\
\hline & $>2$ lobes & 1 \\
\hline \multirow[t]{3}{*}{ Dyspnea, mMRC scale } & $0-11$ & Zero \\
\hline & III-IV & 1 \\
\hline & & TOTAL: $0-9$ points \\
\hline
\end{tabular}

mMRC: modified Medical Research Council.
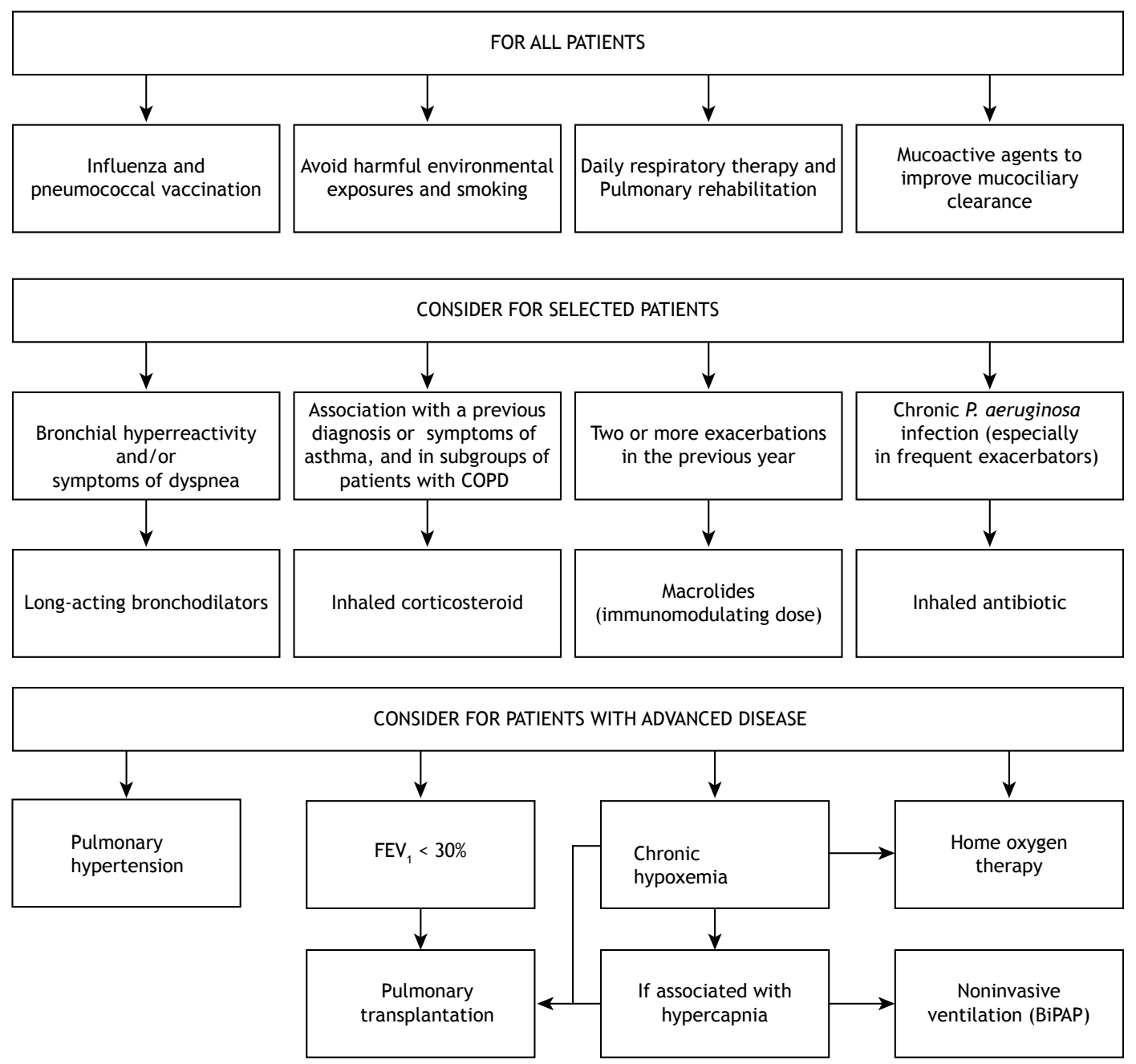

Figure 6. Algorithm for the therapeutic management of stable bronchiectasis patients. BiPAP: bilevel positive airway pressure.

this should not be a criterion for depriving patients of attempts at eradication. ${ }^{(89)}$ Chart 4 presents the main treatment regimens recommended for the treatment of primary $P$. aeruginosa infection. 
Chart 3. Causes of bronchiectasis that have specific treatment.

\begin{tabular}{|c|c|}
\hline Condition or cause & Specific therapeutic measures \\
\hline Allergic bronchopulmonary aspergillosis & Systemic corticosteroids, antifungal agents \\
\hline Ciliary dyskinesia & $\begin{array}{l}\text { Auditory monitoring, cardiac evaluation (malformations), } \\
\text { guidance regarding difficulty in conceiving, mucociliary } \\
\text { clearance techniques }\end{array}$ \\
\hline $\begin{array}{l}\text { Associated diseases (asthma, COPD, collagen } \\
\text { diseases, inflammatory bowel disease, etc.) }\end{array}$ & Treatment of the underlying disease \\
\hline Alpha-1 antitrypsin deficiency & $\begin{array}{l}\text { Avoid tobacco exposure; consider replacement therapy in } \\
\text { specific situations }\end{array}$ \\
\hline Cystic fibrosis & $\begin{array}{l}\text { DNase; consider CFTR modulators (if available and in the } \\
\text { appropriate situation) }\end{array}$ \\
\hline Immunodeficiencies & Periodic immunoglobulin replacement (i.v. or s.c.) \\
\hline Nontuberculous mycobacterial infection & $\begin{array}{l}\text { Treatment according to species and in accordance with national } \\
\text { and international guidelines }\end{array}$ \\
\hline Bronchial obstruction & Bronchoscopic clearance or surgical treatment \\
\hline Gastroesophageal reflux disease & Inhibitor of acid gastric secretion; consider surgery \\
\hline
\end{tabular}

CFTR: cystic fibrosis transmembrane conductance regulator.

With regard to other PPMs, despite their potential deleterious effect on the clinical course of bronchiectasis patients, there is insufficient evidence to justify the adoption of eradication protocols in this context. However, in selected cases, characterized by progressive functional decline and/or severe exacerbation related to the first identification of a PPM, such as methicillin-resistant $S$. aureus, Burkholderia cepacia, Achromobacter xylosoxidans, or Stenotrophomonas maltophilia, an attempt at eradication should be made.

Our recommendation:
Immediately following the first identification of $P$.
aeruginosa in the sputum of a patient, the patient
should be treated with a systemic antipseudomonal
antibiotic combined with an inhaled antibiotic.
Follow-up sputum culture is recommended 2-4
weeks after treatment completion.

\section{Chronic bronchial infection}

In bronchiectasis patients with chronic $P$. aeruginosa infection, antibiotic use is associated with a decrease in sputum bacterial density, improved symptoms, and improved quality of life, as well as with a potential effect in reducing the number of pulmonary exacerbations. ${ }^{(90)}$ Various antibiotic classes and formulations tested have demonstrated clinical benefits, especially in patients who are prone to exacerbations. ${ }^{(91)}$ However, recent randomized clinical trials have shown conflicting results regarding the efficacy of the inhalation route. ${ }^{(92-94)}$

In Brazil, tobramycin and colistimethate are approved by the Brazilian National Health Oversight Agency for the treatment of cystic fibrosis and are marketed in the country; other classes of inhaled antibiotics, such as aztreonam and ciprofloxacin (both as a dry powder formulation and as nebulization of liposomes), are not available. Chart 5 shows the drugs and regimens recommended for the treatment of chronic bronchial infection with $P$. aeruginosa that are available in Brazil. These medications are approved and marketed in the country. Despite their availability in the country, these medications have a high price and are therefore usually obtained through public, high-cost medication dispensation protocols, which currently exist only for patients with bronchiectasis associated with cystic fibrosis. There is no evidence of superiority of one option over the other.

With regard to inhaled gentamicin, it is of note that, in the main clinical trial that tested it (compared with placebo), it was used as long-term therapy. ${ }^{(95)}$ Alternate month use is based on the experience with the use of inhaled antibiotics in cystic fibrosis and is justified because it reduces the emergence of resistant strains.

Bronchospasm is a common adverse effect that can be minimized by using a bronchodilator prior to using an inhaled antibiotic. Hemoptysis as an adverse effect is not uncommon. Whenever possible, formulations developed and tested for inhalation should be preferred to intravenous formulations because of the reduced risk of adverse events.

In patients with chronic infection with PPMs other than $P$. aeruginosa, the lack of evidence does not allow us to recommend the use of inhaled antibiotic therapy. Chronic use of systemic antibiotics (orally or as intravenous cycles) should not be routinely recommended in bronchiectasis patients because of the lack of evidence and the risks associated with repeated exposure to these medications. However, selected cases in which the number of exacerbations remains high and quality of life remains poor, despite optimal treatment, may benefit from this strategy. ${ }^{(96)}$

Our recommendation:
Bronchiectasis patients with chronic $P$. aeruginosa
infection and exacerbations may benefit from and
should be treated with long-term inhaled antibiotics.
The choice will depend on the availability of and
access to medication.


Chart 4. Main treatment regimens recommended for the treatment of primary Pseudomonas aeruginosa infection in bronchiectasis patients.

\begin{tabular}{|c|c|c|}
\hline Treatment regimen & Dose & Frequency \\
\hline \multicolumn{3}{|c|}{ Oral antibiotic + inhaled antibiotic } \\
\hline \multicolumn{3}{|l|}{ Oral: } \\
\hline Ciprofloxacin & $500-750 \mathrm{mg}^{\mathrm{a}}$ & $12 / 12 \mathrm{~h}$ for $14-21$ days \\
\hline \multicolumn{3}{|l|}{+} \\
\hline \multicolumn{3}{|l|}{ Inhaled: } \\
\hline Gentamicin or & $80 \mathrm{mg}$ & $12 / 12 \mathrm{~h}$ for 3 months \\
\hline Nebulized tobramycin or & $300 \mathrm{mg}$ & $12 / 12 \mathrm{~h}$ for 3 months \\
\hline Colistimethate ${ }^{* *}$ & $1,000,000 \mathrm{IU}$ & $12 / 12 \mathrm{~h}$ for 3 months \\
\hline \multicolumn{3}{|c|}{ Intravenous antibiotic (antipseudomonal beta-lactam + aminoglycoside) + inhaled antibiotic } \\
\hline \multicolumn{3}{|l|}{ Intravenous: } \\
\hline Ceftazidime or & $2 \mathrm{~g}$ & $8 / 8$ h (14 days) \\
\hline Cefepime or & $2 g$ & $8 / 8 \mathrm{~h}$ (14 days) \\
\hline Piperacillin + tazobactam or & $4.5 \mathrm{~g}$ & $6 / 6 \mathrm{~h}$ or $8 / 8 \mathrm{~h}$ ( 14 days) \\
\hline Meropenem & $2 \mathrm{~g}$ & $8 / 8$ h (14 days) \\
\hline+ & & \\
\hline \multicolumn{3}{|l|}{ Intravenous: } \\
\hline Amikacin or & $20-30 \mathrm{mg} / \mathrm{kg} /$ day (max $1.5 \mathrm{~g} /$ day) & 24/24 h (14 days) \\
\hline Gentamicin or & $3-5 \mathrm{mg} / \mathrm{kg} /$ day ( $\max 160 \mathrm{mg} / \mathrm{day})$ & 24/24 h (14 days) \\
\hline Tobramycin & 10 mg/kg/day (max 660 mg/day) & 24/24 h (14 days) \\
\hline+ & & \\
\hline \multicolumn{3}{|l|}{ Inhaled: } \\
\hline Gentamicin or & $80 \mathrm{mg}$ & $12 / 12$ h (3 months) \\
\hline Nebulized tobramycin or & $300 \mathrm{mg}$ & $12 / 12$ h (3 months) \\
\hline Colistimethate ${ }^{\mathrm{b}}$ & $1,000,000 \mathrm{IU}$ & $12 / 12$ h (3 months) \\
\hline
\end{tabular}

Max: maximum. ${ }^{a}$ The dose of $750 \mathrm{mg}$, p.o., 12/12 h is indicated for patients weighing more than $50 \mathrm{~kg}$. ${ }^{\mathrm{b} I f}$ inhaled antibiotics are not available, consider treating the primary infection with systemic antibiotics alone.

Chart 5. Inhaled antibiotics available in Brazila and recommended for the treatment of chronic bronchial infection with Pseudomonas aeruginosa in bronchiectasis patients.

\begin{tabular}{lcl}
\multicolumn{1}{c}{ Antibiotic and formulation } & Dose & \multicolumn{1}{c}{ Frequency } \\
\hline Nebulized colistimethate & $1,000,000 \mathrm{IU}$ & $12 / 12 \mathrm{~h}$ continuously \\
Gentamicin & $80 \mathrm{mg}$ & $12 / 12 \mathrm{~h}$ continuously (or in alternating cycles of 28 days) \\
Dry powder tobramycin & $112 \mathrm{mg}$ & $12 / 12 \mathrm{~h}$ in alternating cycles of 28 days \\
Nebulized tobramycin & $300 \mathrm{mg}$ & $12 / 12 \mathrm{~h}$ in alternating cycles of 28 days \\
\hline
\end{tabular}

aSee details in the text regarding access to inhaled antibiotics. 'Some centers dilute the intravenous formulation in $0.9 \%$ saline for nebulization; considerable caution should be exercised because of the risk of more side effects and bronchospasm.

\section{Chronic inflammation}

\section{Macrolides}

Macrolides are the only class of molecules with antibacterial and anti-inflammatory properties, although these immunomodulatory effects are not fully understood. Three large randomized clinical trials of long-term use of macrolides (azithromycin or erythromycin) showed a reduction in the frequency of exacerbations in adults with bronchiectasis who had had one to three exacerbations in the previous year: one involving 141 patients on either azithromycin or placebo for 6 months ${ }^{(97)}$; one with 83 patients treated with either azithromycin or placebo for 12 months $^{(98)}$; and one with 117 patients treated with either erythromycin or placebo for 12 months. ${ }^{\left({ }^{99}\right)}$ A meta-analysis of nine studies (530 patients) demonstrated that macrolide use improved quality of life, reduced the number of patients with exacerbations, and reduced the number of exacerbations per patient. ${ }^{(100)}$ A recent review pointed out that the evidence for the reduction in the frequency of exacerbations and improvement in quality of life is derived from studies of azithromycin, rather than other macrolides, predominantly in adults. ${ }^{(101)}$ Among macrolides, azithromycin has the longest half-life and decreased cell efflux, which means that it reaches higher intracellular levels when administered long-term. The azithromycin doses used in clinical trials or in clinical practice are $500 \mathrm{mg} /$ day or 250 $\mathrm{mg} /$ day three times a week, or $250 \mathrm{mg}$ daily.

The most common adverse effect of macrolides is diarrhea, although treatment discontinuation due to diarrhea is rare. ${ }^{(100,102-105)}$ With long-term use there is also the possibility of increased resistance of oropharyngeal commensal streptococci ${ }^{(98,99)}$ and of emergence of nontuberculous mycobacteria. ${ }^{(15,106)}$

When prescribing macrolides, one should take into account the risk of electrocardiographic QT interval prolongation. Among macrolides, azithromycin poses the lowest risk of QT interval prolongation, whereas erythromycin poses the highest. ${ }^{(107)}$ Cardiac risks 
associated with macrolides are increased in the first 5 days of use. ${ }^{(108)} \mathrm{A}$ meta-analysis of bronchiectasis patients (comparing macrolides with placebo or usual medical care) found no association between macrolide use and an increased risk for adverse cardiac events, ${ }^{(100)}$ but the data are limited and do not allow us to rule out cardiac risk in such patients. ${ }^{(101)}$

It is important that, before the medication is started, an electrocardiogram be performed and the patient's history of cardiac risk factors and use of potentially arrhythmogenic drugs be investigated.

The European Respiratory Society 2017 guidelines ${ }^{(15)}$ recommend macrolides as first-line therapy for patients with no evidence of $P$. aeruginosa infection in order to reduce exacerbations. For individuals infected with this pathogen, macrolides are recommended as second-line therapy, with inhaled antibiotics being the first choice of treatment. ${ }^{(15)}$

\section{Our recommendation:}

Use macrolides as continuous therapy for at least 6-12 months for bronchiectasis patients with at least two exacerbations per year. Prefer azithromycin. The use of macrolides may be considered, although there is no evidence, for patients with fewer than two exacerbations per year but with a history of severe exacerbations or primary or secondary immunodeficiency, those whose exacerbations have a significant impact on their quality of life, and those with more severe bronchiectasis. Active nontuberculous mycobacterial infection should be ruled out.

\section{Inhaled corticosteroids}

Bronchiectasis patients have airway inflammation and, sometimes, symptoms similar to those of asthma or COPD. A recent review found only seven randomized placebo-controlled studies on the use of inhaled corticosteroids in bronchiectasis. All of those studies involved adults with stable disease, only one of which assessed long-term outcomes (over 6 months), and there was insufficient evidence to support the routine use of inhaled corticosteroids. There are no studies on the use of inhaled corticosteroids during exacerbations or in children, and there is not enough data on unwanted side effects. ${ }^{(109)}$

According to the aforementioned guidelines, ${ }^{(15)}$ inhaled corticosteroids play no role in the routine management of bronchiectasis. Routine treatment with inhaled corticosteroids is recommended only if there is associated asthma or in the subgroup of patients with COPD and an indication for inhaled corticosteroid use. ${ }^{(15)}$

\section{Our recommendation:}

There is insufficient evidence to support the routine use of inhaled corticosteroids in adults with bronchiectasis. Inhaled corticosteroid therapy may be justified in some subgroups of adults if there is associated asthma or COPD.

\section{Airflow obstruction}

\section{Bronchodilators}

Most bronchiectasis patients have airflow obstruction, ${ }^{(110)}$ but other spirometric patterns (reduced FVC, mixed patterns, or preserved pulmonary function) can also be observed. ${ }^{(15)}$ There are few controlled studies that have assessed bronchodilator therapy in bronchiectasis. There is no evidence to support the routine use of bronchodilators in patients without dyspnea or respiratory symptoms, because there are no randomized controlled studies investigating the effectiveness of the use of short-acting ${ }^{(111)}$ or longacting ${ }^{(112)} \beta_{2}$ agonists. There is limited and indirect evidence for the benefit of long-term treatment with bronchodilators, evidence extracted from a study that compared a high-dose inhaled corticosteroid with a medium-dose long-acting $\beta_{2}$ agonist/inhaled corticosteroid combination. ${ }^{(113)}$ In that study, combination therapy was advantageous, there being a decrease in dyspnea, better cough control, better quality of life, and a reduction in the use of rescue medication ( $\beta_{2}$ agonists). However, the study did not report on improvement in pulmonary function, the types of pathogens isolated, or increased adverse effects. ${ }^{(113)}$

With regard to anticholinergics, there are no recent studies, and none of the few existing studies has met criteria for inclusion in systematic reviews, which means that there is no evidence to recommend the routine use of anticholinergics. The older drugs tend to dry secretions and reduce mucociliary transport, with potential deleterious effects. ${ }^{(114)}$

Guidelines on bronchiectasis recommend that long-acting bronchodilators be used only when bronchiectasis is associated with asthma or COPD, ${ }^{(15,47)}$ since there is no evidence beyond that which exists for these conditions. ${ }^{(112,114)}$ Spanish guidelines, ${ }^{(85)}$ as well as those of the European Respiratory Society, ${ }^{(15)}$ recommend the use of long-acting bronchodilators in symptomatic patients with airflow obstruction; the latter ${ }^{(15)}$ recommend treatment discontinuation if there is reduction in symptoms, whereas the former ${ }^{(85)}$ additionally recommend the use of shortacting bronchodilators prior to respiratory therapy and prior to the use of inhaled hypertonic solutions and/or inhaled antibiotics.

\section{Our recommendation:}

There is insufficient data to recommend the routine use of bronchodilators in bronchiectasis patients without dyspnea. Long-acting bronchodilators may be recommended if bronchiectasis is associated with asthma or COPD. Because of the potential risk of bronchospasm resulting from the use of inhaled mucoactive drugs and inhaled antibiotics, it is suggested that bronchodilators be used prior to using these drugs. 


\section{Airway clearance}

In bronchiectasis, the changes in mucociliary clearance contribute to secretion retention and mucus plugging in the airways; a variety of techniques have been developed to optimize the removal of secretions and mucus. ${ }^{(115)}$

\section{Respiratory therapy}

Despite the lack of consistent evidence, ${ }^{(116,117)}$ airway clearance techniques are the standard treatment for people with bronchiectasis. ${ }^{(47,118)}$ Among independently performed techniques, active cycle of breathing, thoracic expansion exercises, forced expiration techniques, and autogenic drainage are recommended. These techniques can be aided by postural drainage and by modified postural drainage (postural drainage without head-down tilt). In addition, there are devicedependent techniques: positive expiratory pressure and intrathoracic oscillating positive expiratory pressure-the Flutter ${ }^{\circledR}$ (Scandipharm, Birmingham, AL, USA) and the Acapella $\AA$ (Smiths Medical, Dublin, $\mathrm{OH}$, USA); and extrathoracic oscillations-high-frequency chest wall oscillation with a vest (high-frequency airway clearance). ${ }^{(47,115,117,119)}$ During an infectious exacerbation or when the patient is very fatigued, manual techniques can be offered as part of the airway clearance technique regimen. ${ }^{(47)}$

The use of intermittent positive pressure breathing lacks direct supporting evidence; however, this technique has been used as an adjuvant to reduce the work of breathing, increase tidal volume, and mobilize secretions, being used for supporting critically ill patients with airway clearance difficulties. ${ }^{(47,115)}$ The choice of a technique should take into consideration patient preference, patient adherence, impacts on daily life, and presence of comorbidities. ${ }^{(85)}$

Our recommendation:

Respiratory therapy techniques for improving mucociliary clearance should be applied and taught to all bronchiectasis patients with chronic production of secretions and/or (CT scan) signs of mucus plugging.

\section{Physical exercise/pulmonary rehabilitation}

In a systematic review ${ }^{(120)}$ on pulmonary rehabilitation (exercise and education) or exercise training in bronchiectasis patients, four trials with 164 participants were included. Incremental shuttle walk distance and quality-of-life scores were found to improve after the intervention, but these benefits were not sustained at 6 months. There was no effect on cough- or symptom-related quality of life. The frequency of exacerbations over 12 months was reduced with exercise training, but pulmonary rehabilitation initiated during an exacerbation had no impact on exacerbation frequency or mortality. The authors concluded that pulmonary rehabilitation and exercise training programs produce short-term improvements in exercise capacity.
One study on pulmonary rehabilitation ( 8 weeks of supervised exercise training and review of physical therapy techniques) reported reduced frequency of exacerbations over a 12-month follow-up period and extended time to first exacerbation. ${ }^{(121)}$

European $^{(15)}$ and Spanish( ${ }^{(85)}$ guidelines recommend that patients who have exertional limitation (mMRC scale score $>1$ ) should be encouraged to exercise regularly and participate in pulmonary rehabilitation programs.

Our recommendation:

Refer bronchiectasis patients with exertional limitation for regular exercise and participation in pulmonary rehabilitation programs, if available.

\section{Osmotic agents}

Infection and inflammation reduce airway surface fluid height, impairing mucociliary clearance. There are two hyperosmolar agents with mucoactive properties: hypertonic saline and mannitol. However, even $0.9 \%$ saline may have mucoactive properties. Evidence suggests that $6-7 \%$ hypertonic saline changes sputum rheology, enabling better clearance by the cilia. ${ }^{(122)}$

A systematic review ${ }^{(123)}$ identified two studies that showed that the use of hypertonic saline brings benefits. Inhaled hypertonic saline (7\%) as an adjuvant to respiratory therapy for 4 weeks was more effective in promoting expectoration than was isotonic saline. ${ }^{(124)}$ In another study, the use of hypertonic saline compared with $0.9 \%$ saline improved quality of life and pulmonary function, as well as reduced emergency room visits. ${ }^{(125)}$ However, a 12-month study comparing the use of hypertonic saline with $0.9 \%$ saline showed that there were no differences in exacerbation rates, quality-of-life scores, $\mathrm{FEV}_{1}$, or reduction in bacterial colonization of sputum. (126) Although there is no commercial formulation of hypertonic saline $(6 \%$ or $7 \%$ ) on the market in Brazil, hypertonic saline can be easily prepared at pharmacies.

A systematic review ${ }^{(123)}$ identified five studies on the use of mannitol in adults, showing benefits in mucus clearance and in expectoration properties. However, those studies had very small samples. In a study involving 461 patients, inhaled mannitol (400 mg) was tested for 12 months in bronchiectasis patients. During the study period, there was no reduction in the exacerbation rate; however, there was improvement in quality of life and in the time to first exacerbation. ${ }^{(127)}$

\section{Our recommendation:}

The use of hypertonic saline (6-7\%) should be considered in bronchiectasis patients with persistent secretions despite other measures. The first administration of hypertonic saline should be supervised to assess for adverse effects (bronchospasm), which can be prevented or minimized by prior administration of a short-acting bronchodilator.

\section{Mucolytics}

There is no evidence to support the use of $\mathrm{N}$-acetylcysteine or guaiafenesin in bronchiectasis. ${ }^{(122,123)}$ 
Mucokinetic agents such as beta-agonists have the potential to improve mucociliary clearance. ${ }^{(128)}$ European guidelines ${ }^{(15)}$ recommend trying using mucolytics for 3 months for patients who have difficulty expectorating and therefore have a poor quality of life.

There are only two randomized studies that have analyzed the use of DNase. ${ }^{(68,129)}$ The first $^{(129)}$ did not identify significant changes in spirometry, quality of life, dyspnea, or mucus transportability. The second ${ }^{(68)}$ showed that the rates of pulmonary exacerbation and the decline in $\mathrm{FEV}_{1}$ were significantly greater in the group treated with DNase.

Our recommendation:
There is insufficient evidence to recommend the
routine use of mucolytics in bronchiectasis patients.
The use of DNase is contraindicated for adult non-
cystic fibrosis bronchiectasis patients.

\section{Vaccines}

Bronchiectasis patients are at an increased risk of developing pneumonia and having a high number of exacerbations of viral etiology. ${ }^{(130)}$ Influenza caused by Influenza A and B virus increases the morbidity and mortality of patients with chronic diseases, as well as predisposing them to secondary bacterial pneumonia. ${ }^{(131)}$ A prospective observational study evaluated 3,495 inpatients with community-acquired pneumonia (CAP) between 2000 and 2011. ${ }^{(132)}$ Patients with non-cystic fibrosis bronchiectasis and CAP represented $2 \%$ of the sample and had characteristics and clinical results similar to those of the other patients. Despite the high prevalence of $P$. aeruginosa as the etiologic agent of CAP, Streptococcus pneumoniae was the most commonly isolated agent (44.4\% vs. $42.7 \% ; p=0.821$ ). This finding motivated the authors to recommend influenza and pneumococcal vaccination for bronchiectasis patients. ${ }^{(132)}$

Two types of influenza vaccines are regulated and available for use in Brazil, the trivalent and quadrivalent influenza vaccines, ${ }^{(133)}$ and all patients with chronic respiratory diseases should be vaccinated annually, unless they have a contraindication. ${ }^{(134)}$

With regard to pneumococcal vaccines, the Brazilian Immunization Association and the SBPT recommend the following sequence for patients with chronic lung diseases: 13-valent pneumococcal conjugate vaccine (PCV13), which has stronger immunogenic effect, and, 1 year later, 23-valent pneumococcal polysaccharide vaccine (PPSV23); the PPSV23 can be boosted by a second dose administered 5 years after the first dose. If the individual has been vaccinated with PPSV23, it is appropriate to wait 1 year after PPSV23 before giving a dose of PCV13. (134)

\section{Our recommendation:}

Bronchiectasis patients should receive influenza vaccine annually and should receive PCV13 and PPSV23 in the sequence recommended by the Brazilian Immunization Association and the SBPT.

\section{Treatment of chronic respiratory failure}

\section{Home oxygen therapy and noninvasive ventilation}

$\mathrm{PaO}_{2}<60 \mathrm{mmHg}$ is indicative of severe bronchiectasis and the possible need for long-term home oxygen therapy (18-24 h per day). Oxygen therapy may delay the onset of cor pulmonale, one of the factors related to morbidity and mortality in this specific group of patients, in addition to hypoxemia and hypercapnia. ${ }^{(135)}$

The indications for home oxygen therapy should be the same as those for chronic airway diseases, that is, $\mathrm{PaO}_{2}<55 \mathrm{mmHg}$ or $\mathrm{SpO}_{2}<88 \%$ on room air or $\mathrm{PaO}_{2}$ between 56 and $59 \mathrm{mmHg}$ associated with cor pulmonale and/or hematocrit > 55\%.(136)

Noninvasive mechanical ventilation may be indicated in patients with chronic respiratory failure with hypercapnia, as an adjuvant treatment to cardiopulmonary rehabilitation and respiratory therapy, as well as being indicated as supportive therapy in patients waiting for lung transplantation. It should be emphasized that noninvasive mechanical ventilation should be used with caution or should even be contraindicated if there is excessive bronchopulmonary secretion; noninvasive mechanical ventilation is therefore indicated mainly for phases that are clinically stable from a secretion point of view. Among the different possible modes of noninvasive mechanical ventilation, the most convenient is bilevel positive airway pressure (BiPAP). ${ }^{(15,85)}$

Our recommendation:
In patients with chronic hypoxemia despite optimal
clinical treatment, long-term home oxygen therapy
is indicated. In clinically stable patients with chronic
hypercapnic respiratory failure, noninvasive mechanical
ventilation by BiPAP should be used as an adjuvant to
cardiopulmonary rehabilitation and respiratory therapy.

\section{Lung transplantation}

Lung transplantation is indicated for adult individuals with chronic, end-stage lung disease or evidence of disease progression who are at a high (> 50\%) risk of death within 2 years despite full optimal treatment, unless they have an absolute contraindication. ${ }^{(85,137)}$ There are no specific recommendations on the timing of referring non-cystic fibrosis bronchiectasis patients for lung transplantation, which means that the recommendations are based on those proposed for other chronic lung diseases and for bronchiectasis associated with cystic fibrosis. ${ }^{(137,138)}$

Lung transplantation should be considered for individuals with diffuse bronchiectasis who have a progressive decline in pulmonary function despite full clinical treatment. ${ }^{(139,140)}$ Progression of the underlying disease with severe impairment of pulmonary function ( $\mathrm{FEV}_{1}<30 \%$ of predicted); presence of hypoxemia (requiring home oxygen therapy) and hypercapnia; need for noninvasive ventilation; severe exacerbations and frequent hospitalizations; and development of pulmonary hypertension are signs that the patient should be referred for lung transplantation. $85,139,141)$ 
In three series of transplant recipients, 1-, 5-, and 10 -year survival was, respectively, between $68 \%$ and $85 \%{ }^{(142-144)}$ between $61 \%$ and $73 \%,{ }^{(142-144)}$ and $48 \% .^{(143)}$ In those studies, (sequential) bilateral transplantation was more common than unilateral transplantation. Since bronchiectasis is a suppurative lung disease, bilateral transplantation is always indicated.

Our recommendation:
Lung transplantation should be considered for
patients with $\mathrm{FEV}_{1}<30 \%$ of predicted or for
those with higher $\mathrm{FEV}_{1}$ values but with rapid lung
function decline. Some factors, if present, should
alert to the possibility of early referral of the
patient for lung transplantation evaluation. These
factors include severe and frequent exacerbations,
with ICU admissions; recurrent or treatment-
refractory pneumothorax or hemoptysis; chronic
respiratory failure; and hypercapnia or pulmonary
hypertension.

\section{Surgical treatment}

Surgical resection is a potentially curative treatment for patients with localized disease refractory to clinical treatment. Palliative surgical treatment (diffuse disease) should be reserved only for cases of severe hemoptysis with ineffective embolization or cases of abscessed areas unresponsive to antimicrobial treatment and associated measures. ${ }^{(15,145)}$

Lobectomy in chronic inflammatory lung diseases can be performed safely by thoracoscopy, and the rate of conversion to thoracotomy is low. ${ }^{(146,147)}$ Surgery by video-assisted thoracoscopy reduces hospital stays and has a lower rate of complications, especially with regard to bleeding, when compared with surgery by thoracotomy. ${ }^{(148)}$

In a specific group of patients with focal disease unresponsive to clinical treatment, resection was associated with a significant improvement in symptoms and an acceptable risk of morbidity and mortality. ${ }^{(149)}$ A meta-analysis revealed a mortality rate of $1.5 \%$ and an improvement in symptoms in $66.5 \%$ of patients. ${ }^{(145)}$ In one study, quality of life after 1 year of follow-up was reported as excellent in $73.3 \%$ of patients and as unchanged in only $8.3 \%$. $^{(150)}$ One group of authors also demonstrated that quality of life improved and exercise capacity was preserved in selected surgical patients. ${ }^{(151)}$ The presence of residual bronchiectasis, nontuberculous mycobacterial infection, or immunosuppression can be risk factors for poor clinical response after surgery. The underlying disease is also a determinant of therapeutic decision. ${ }^{145,152)}$

Our recommendation:

Surgical treatment should be reserved for individuals with localized bronchiectasis refractory to clinical treatment, and video-assisted thoracoscopy is the procedure of choice.

\section{THERAPEUTIC MANAGEMENT OF EXACERBATIONS}

\section{Definition and role of exacerbations}

An exacerbation is characterized by worsening of three or more of the following symptoms for at least $48 \mathrm{~h}: 1$ ) cough; 2) sputum volume or viscosity; 3) sputum purulence; 4) dyspnea or exercise intolerance; 5) fatigue; and 6) hemoptysis. ${ }^{(153)}$

Chest X-ray may show preexisting bronchiectasis filled with secretion, with no signs of consolidation. The diagnosis is clinical, and ancillary tests can be used for differential diagnoses, such as pneumonia, pneumothorax, pulmonary thromboembolism, and heart diseases.

The causes of exacerbations are not fully understood, but a relationship is known to exist between chronic bronchial bacterial infection and inflammation. Viral infections or other bacteria can trigger an imbalance in this relationship. ${ }^{(10,154)}$

In addition to having a major impact on patient quality of life, exacerbations increase health care costs. Another important consequence is higher mortality rates, since patients with more than three exacerbations or a hospitalization in the previous 12 months experience increased mortality. ${ }^{(155,156)}$

\section{Severity of exacerbations}

Once an exacerbation is diagnosed, history taking and physical examination should be targeted at determining the severity of the attack. Severe exacerbations require intravenous antibiotic therapy and/or hospitalization. Signs indicating the severity of an exacerbation are as follows ${ }^{(47,85,157)}$ : respiratory rate $\geq 25$ breaths/min; respiratory distress with use of accessory muscles; deterioration of oxygen saturation; cyanosis; body temperature $\geq 38^{\circ} \mathrm{C}$; or another criterion for sepsis and hemoptysis ( $>25 \mathrm{~mL}$ in $24 \mathrm{~h}$ ). Patients with hemodynamic instability, an altered level of consciousness, or mental confusion should be considered for ICU treatment. Unavailability of home intravenous therapy may lead to the need for hospitalization in patients who used oral antibiotics and showed no response to treatment.

It is of note that chronic infection with $P$. aeruginosa is associated with more frequent hospital admissions, longer hospital stays, worse pulmonary function, and higher mortality. ${ }^{(73,158)}$ Therefore, patients with chronic infection with $P$. aeruginosa should be carefully evaluated for exacerbation severity.

Among inpatients, predictors of higher mortality include male gender, use of systemic corticosteroids, low $\mathrm{FEV}_{1}$, increased creatinine, history of smoking, and need for mechanical ventilation. ${ }^{(159)}$

\section{Treatment of exacerbations}

\section{Choice of antibiotic therapy}

The use of antibiotics is essential for treating exacerbations in bronchiectasis. Upon diagnosis of an 
exacerbation, sputum sample collection is indicated, but treatment initiation should not wait for results, which will be used only if the patient does not respond adequately to the initially chosen treatment. The choice of an antibiotic regimen should take into consideration results of previous aerobic sputum cultures and response to antibiotics in previous exacerbations, as illustrated in Figure 7. Regardless of the antibiotic chosen, it is always suggested that the maximum recommended doses be used in order to ensure better penetration of the drug into dilated, structurally altered airways with accumulation of secretions.

\section{Duration of treatment}

Few studies have evaluated the duration of treatment for exacerbations. Currently, 14-day to 21-day treatment courses are recommended. In mild cases, in which the patient rapidly returns to baseline symptoms after treatment initiation, a treatment course of only 10 days can be considered. ${ }^{(15)}$
There is no literature evidence on which outcomes are the best for use in determining the resolution of exacerbations. For patients with severe exacerbations, it is recommended that clinical improvement be associated with inflammatory markers and pulmonary function (spirometry or PEF). There is a significant increase in leukocytes, neutrophils, CRP, and fibrinogen in exacerbations; however, a small percentage of patients do not show inflammatory improvement by the end of treatment. Pulmonary function declines in exacerbations, and often recovers within 2 weeks of treatment completion. The greater the decline is, the greater is the risk of a long recovery period. ${ }^{(160-162)}$

\section{Other therapeutic measures}

There is little evidence to support the use of other medications and adjuvant measures; however, some may be considered in specific situations:

- Systemic corticosteroids: Systemic corticosteroids should be used if there is associated asthma or

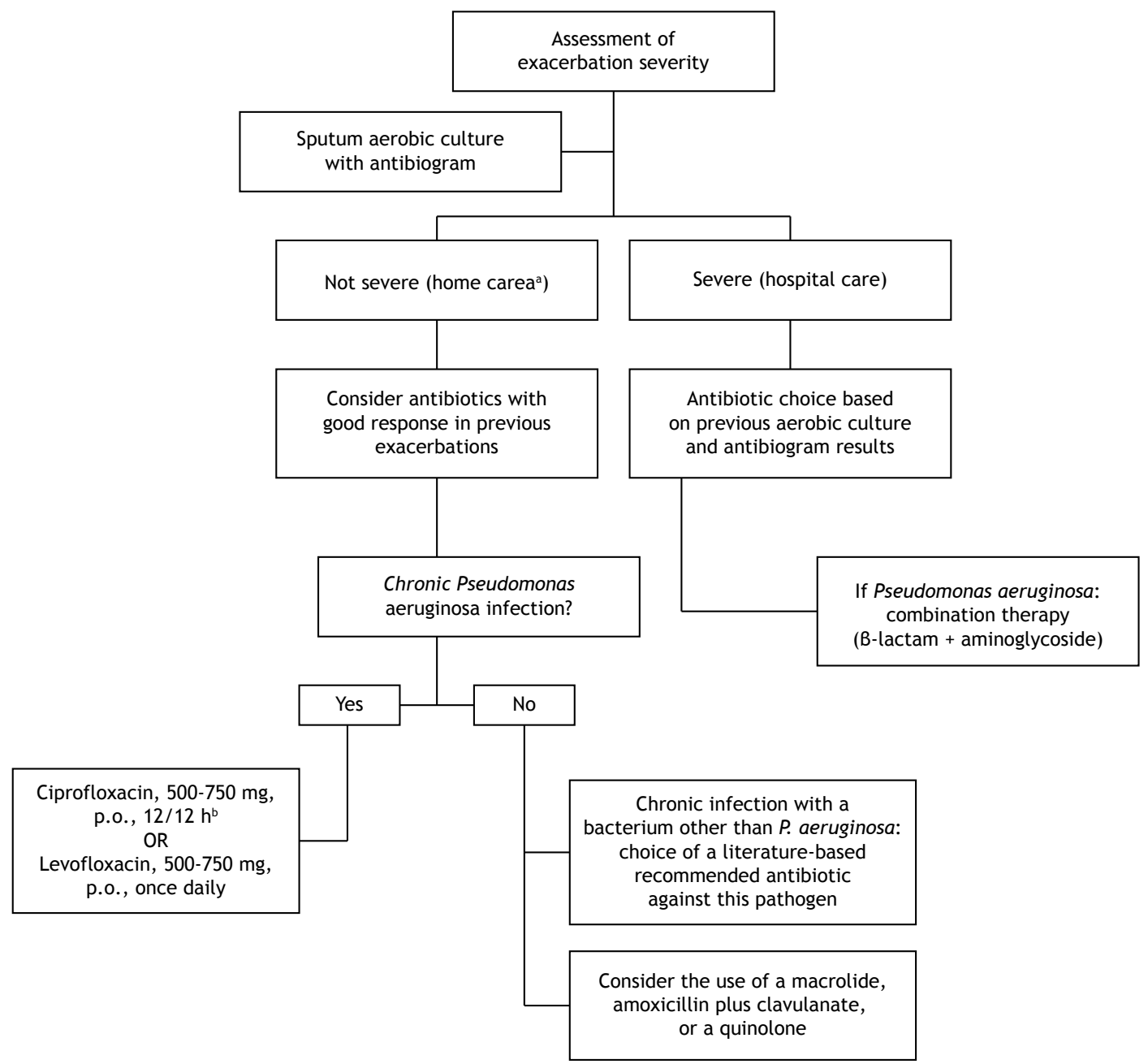

Figure 7. Flow chart for the therapeutic management of exacerbations. aIf intravenous treatment is necessary in nonsevere exacerbations, consider the possibility of intravenous administration at home. ${ }^{\circ}$ The dose of ciprofloxacin, 750 $\mathrm{mg}, 12 / 12 \mathrm{~h}$ should be reserved for severe exacerbations in patients weighing more than $50 \mathrm{~kg}$. 
COPD. They may be considered in patients with hypersecretion, at low doses $(0.25$ to $0.5 \mathrm{mg} /$ $\mathrm{kg}$ of prednisone or equivalent), with attention being paid to the risks of side effects.

- Inhaled bronchodilators: Inhaled bronchodilators may be added to treat patients with significant dyspnea, especially during hospitalization, always taking into consideration the possible adverse events.

- Respiratory therapy: It is recommended that exercises for bronchial hygiene be increased during an exacerbation, regardless of the technique usually used by the patient. In cases of hospitalization, daily follow-up with a physical therapist, at least two sessions per day, is indicated.

- Hyperosmolar agents: Hyperosmolar agents may be considered in order to improve bronchial hygiene. The most commonly used option is hypertonic saline, starting at $3 \%$, with the possibility of increasing up to a concentration of $7 \%$ if well tolerated. Because of the risk of hyperosmolar-induced bronchospasm, rapid-onset bronchodilators should be used 15-30 min prior to inhalation and the patient should be supervised when using a hyperosmolar agent for the first time.
Inhaled antibiotics: Inhaled antibiotics are not routinely recommended for the treatment of exacerbations. If the patient is already using chronic inhaled antibiotics, he/she can continue the medication as long as the risks of side effects from concurrent use of inhaled and systemic antibiotic therapy are assessed. ${ }^{(163,164)}$

\section{Our recommendation}

Once an exacerbation is diagnosed, the severity of the exacerbation should be determined in order to decide between home care and hospitalization. Before initiating antibiotic therapy (based on previous culture results), another sputum sample should be collected for microbiological analysis, the results of which will be used if there is no response to treatment. Adjuvant measures (use of corticosteroids, bronchodilators, respiratory therapy, and/or hypertonic agents) should be instituted based on clinical judgment.

\section{FINAL CONSIDERATIONS}

Chart 6 summarizes the recommendations for the follow-up and treatment of non-cystic fibrosis bronchiectasis patients.

Chart 6. Chart of recommendations for follow-up and treatment of non-cystic fibrosis bronchiectasis patients.

\begin{tabular}{|c|c|c|c|}
\hline \multicolumn{4}{|c|}{ Recommendations } \\
\hline \multirow[t]{4}{*}{ Follow-up } & $\begin{array}{l}\text { Functional } \\
\text { aspects }\end{array}$ & & $\begin{array}{l}\text { Perform spirometry with bronchodilator use every } 6 \text { months, } \\
\text { lung volume assessment (if available) annually, and the } \\
\text { six-minute walk test (at the physician's discretion). }\end{array}$ \\
\hline & $\begin{array}{l}\text { Microbiologic } \\
\text { aspects }\end{array}$ & & $\begin{array}{l}\text { Collect samples from the lower respiratory tract (sputum, } \\
\text { for example) at regular intervals of } 3-4 \text { months and during } \\
\text { pulmonary exacerbations for aerobic culture, as well as } \\
\text { annually for culture for fungi and mycobacteria. If the patient } \\
\text { is being treated with chronic macrolide therapy, culture for } \\
\text { mycobacteria should be performed every } 6 \text { months. }\end{array}$ \\
\hline & Systemic markers & & $\begin{array}{l}\text { Although CRP appears to be an inflammation-related marker } \\
\text { and is available for use in clinical practice, there is insufficient } \\
\text { evidence to recommend its routine use to assess disease severity. }\end{array}$ \\
\hline & $\begin{array}{l}\text { Severity and } \\
\text { prognostic scores }\end{array}$ & & $\begin{array}{l}\text { A severity score and a prognostic estimate should be calculated } \\
\text { at the time patients are diagnosed with bronchiectasis. } \\
\text { Periodic calculation of the score (annually, for example) aids in } \\
\text { therapeutic management. To date, the FACED and the E-FACED } \\
\text { scores are the ones that have been validated for use in Brazil. }\end{array}$ \\
\hline \multirow[t]{2}{*}{$\begin{array}{l}\text { Treatment of } \\
\text { stable patients }\end{array}$} & $\begin{array}{l}\text { Chronic airway } \\
\text { infection }\end{array}$ & $\begin{array}{l}\text { Primary } \\
\text { infection }\end{array}$ & $\begin{array}{l}\text { Immediately following the first identification of } P \text {. aeruginosa in } \\
\text { the sputum of a patient, the patient should be treated with a } \\
\text { systemic antipseudomonal antibiotic combined with an inhaled } \\
\text { antibiotic. Follow-up sputum culture is recommended } 2-4 \text { weeks } \\
\text { after treatment completion. }\end{array}$ \\
\hline & & $\begin{array}{l}\text { Chronic } \\
\text { bronchial } \\
\text { infection }\end{array}$ & $\begin{array}{l}\text { Bronchiectasis patients with chronic Pseudomonas aeruginosa } \\
\text { infection and exacerbations may benefit from and should be } \\
\text { treated with long-term inhaled antibiotics. The choice will } \\
\text { depend on the availability of and access to medication. }\end{array}$ \\
\hline
\end{tabular}

CRP: C-reactive protein; FACED: acronym for Exacerbation, FEV , Age, Chronic colonization with Pseudomonas aeruginosa, Extent (of CT findings), and Dyspnea; BD: bronchodilator; PCV13: 13-valent pneumococcal conjugate vaccine; PPSV23: 23-valent pneumococcal polysaccharide vaccine; SBIm: Sociedade Brasileira de Imunização (Brazilian Immunization Association); SBPT: Sociedade Brasileira de Pneumologia e Tisiologia (Brazilian Thoracic Association); and BiPAP: bilevel positive airway pressure. 


\begin{tabular}{|c|c|c|}
\hline \multicolumn{3}{|c|}{ Recommendations } \\
\hline \multirow[t]{2}{*}{$\begin{array}{l}\text { Chronic } \\
\text { inflammation }\end{array}$} & Macrolides & $\begin{array}{l}\text { Use macrolides as continuous therapy for at least 6-12 months for } \\
\text { bronchiectasis patients with at least two exacerbations per year. } \\
\text { Prefer azithromycin. The use of macrolides may be considered, } \\
\text { although there is no evidence, for patients with fewer than two } \\
\text { exacerbations per year but with a history of severe exacerbations } \\
\text { or primary or secondary immunodeficiency, those whose } \\
\text { exacerbations have a significant impact on their quality of life, } \\
\text { and those with more severe bronchiectasis. Active nontuberculous } \\
\text { mycobacterial infection should be ruled out. }\end{array}$ \\
\hline & $\begin{array}{l}\text { Inhaled } \\
\text { corticosteroids }\end{array}$ & $\begin{array}{l}\text { There is insufficient evidence to support the routine use of } \\
\text { inhaled corticosteroids in adults with bronchiectasis. Inhaled } \\
\text { corticosteroid therapy may be justified in some subgroups of } \\
\text { adults if there is associated asthma or COPD. }\end{array}$ \\
\hline Bronchodilators & & $\begin{array}{l}\text { There is insufficient data to recommend the routine use of } \\
\text { BDs in bronchiectasis patients without dyspnea. Long-acting } \\
\text { BDs may be recommended if bronchiectasis is associated with } \\
\text { asthma or COPD. Because of the potential risk of bronchospasm } \\
\text { resulting from the use of inhaled mucoactive drugs and inhaled } \\
\text { antibiotics, it is suggested that BDs be used prior to using } \\
\text { these drugs. }\end{array}$ \\
\hline \multirow[t]{4}{*}{ Airway clearance } & $\begin{array}{l}\text { Respiratory } \\
\text { therapy }\end{array}$ & $\begin{array}{l}\text { Respiratory therapy techniques for improving mucociliary } \\
\text { clearance should be applied and taught to all bronchiectasis } \\
\text { patients with chronic production of secretions and/or (CT scan) } \\
\text { signs of mucus plugging. }\end{array}$ \\
\hline & $\begin{array}{l}\text { Physical exercise } \\
\text { and pulmonary } \\
\text { rehabilitation }\end{array}$ & $\begin{array}{l}\text { Refer bronchiectasis patients with exertional limitation for } \\
\text { regular exercise and participation in pulmonary rehabilitation } \\
\text { programs, if available. }\end{array}$ \\
\hline & Osmotic agents & $\begin{array}{l}\text { The use of hypertonic saline (6-7\%) should be considered in } \\
\text { bronchiectasis patients with persistent secretions despite other } \\
\text { measures. Hypertonic saline should be first administered under } \\
\text { supervision to assess for adverse effects (bronchospasm), which } \\
\text { can be prevented or minimized by prior administration of a } \\
\text { short-acting bronchodilator. }\end{array}$ \\
\hline & Mucolytics & $\begin{array}{l}\text { There is insufficient evidence to recommend the routine use } \\
\text { of mucolytics in bronchiectasis patients. The use of DNase is } \\
\text { contraindicated for adult non-cystic fibrosis bronchiectasis } \\
\text { patients. }\end{array}$ \\
\hline Vaccines & & $\begin{array}{l}\text { Bronchiectasis patients should receive influenza vaccine } \\
\text { annually and should receive PCV } 13 \text { and PPSV } 23 \text { in the sequence } \\
\text { recommended by the SBIm and the SBPT. }\end{array}$ \\
\hline \multirow[t]{2}{*}{$\begin{array}{l}\text { Chronic } \\
\text { respiratory failure }\end{array}$} & $\begin{array}{l}\text { Home oxygen } \\
\text { therapy and } \\
\text { noninvasive } \\
\text { ventilation }\end{array}$ & $\begin{array}{l}\text { In patients with chronic hypoxemia despite optimal clinical } \\
\text { treatment, long-term home oxygen therapy is indicated. In } \\
\text { clinically stable patients with chronic hypercapnic respiratory } \\
\text { failure, noninvasive mechanical ventilation by BiPAP should } \\
\text { be used as an adjuvant to cardiopulmonary rehabilitation and } \\
\text { respiratory therapy. }\end{array}$ \\
\hline & $\begin{array}{l}\text { Lung } \\
\text { transplantation }\end{array}$ & $\begin{array}{l}\text { Lung transplantation should be considered for patients with } \\
\text { FEV }{ }_{1}<30 \% \text { of predicted or for those with higher FEV } \text { values } \\
\text { but with rapid lung function decline. Some factors, if present, } \\
\text { should alert to the possibility of early referral of the patient for } \\
\text { lung transplantation evaluation. These factors include severe } \\
\text { and frequent exacerbations, with ICU admissions; recurrent } \\
\text { or treatment-refractory pneumothorax or hemoptysis; } \\
\text { chronic respiratory failure; and hypercapnia or pulmonary } \\
\text { hypertension. }\end{array}$ \\
\hline
\end{tabular}

CRP: C-reactive protein; FACED: acronym for Exacerbation, FEV $_{1}$, Age, Chronic colonization with Pseudomonas aeruginosa, Extent (of CT findings), and Dyspnea; BD: bronchodilator; PCV13: 13-valent pneumococcal conjugate vaccine; PPSV23: 23-valent pneumococcal polysaccharide vaccine; SBIm: Sociedade Brasileira de Imunização (Brazilian Immunization Association); SBPT: Sociedade Brasileira de Pneumologia e Tisiologia (Brazilian Thoracic Association); and BiPAP: bilevel positive airway pressure. 
Chart 6. Continued...

\begin{tabular}{lll} 
& $\begin{array}{l}\text { Surgical } \\
\text { treatment }\end{array}$ & $\begin{array}{l}\text { Recommendations } \\
\text { localized bronchiectasis refractory to clinical treatment, and } \\
\text { video-assisted thoracoscopy is the procedure of choice. }\end{array}$ \\
\hline $\begin{array}{l}\text { Treatment of } \\
\text { exacerbations }\end{array}$ & $\begin{array}{l}\text { Once an exacerbation is diagnosed, the severity of the } \\
\text { exacerbation should be determined in order to decide between } \\
\text { home care and hospitalization. Before initiating antibiotic }\end{array}$ \\
& $\begin{array}{l}\text { therapy (based on previous culture results), another sputum } \\
\text { sample should be collected for microbiological analysis, } \\
\text { the results of which will be used if there is no response } \\
\text { to treatment. Adjuvant measures (use of corticosteroids, } \\
\text { bronchodilators, respiratory therapy, and/or hypertonic agents) } \\
\text { should be instituted based on clinical judgment. }\end{array}$ \\
\hline
\end{tabular}

CRP: C-reactive protein; FACED: acronym for Exacerbation, FEV $_{1}$, Age, Chronic colonization with Pseudomonas aeruginosa, Extent (of CT findings), and Dyspnea; BD: bronchodilator; PCV13: 13-valent pneumococcal conjugate vaccine; PPSV23: 23-valent pneumococcal polysaccharide vaccine; SBIm: Sociedade Brasileira de Imunização (Brazilian Immunization Association); SBPT: Sociedade Brasileira de Pneumologia e Tisiologia (Brazilian Thoracic Association); and BiPAP: bilevel positive airway pressure.

\section{REFERENCES}

1. Barker AF, Bardana EJ Jr. Bronchiectasis: update of an orphan disease. Am Rev Respir Dis. 1988;137(4):969-78. https://doi. org/10.1164/ajrccm/137.4.969

2. Brasil. Ministério da Saúde. Secretária de Vigilância à Saúde [homepage on the Internet]. Brasilia: Ministério da Saúde [cited 2019 Apr 1]. Perfil da morbimortalidade por doenças respiratórias crônicas no Brasil, 2003 a 2013. Boletim Epidemiológico. 2016:47(19). [Adobe Acrobat document, 9 p.]. Available from: http://portalarquivos2.saude. gov.br/images/pdf/2016/maio/06/2015-026-doencas-respiratoriascronicas.pdf

3. Chandrasekaran R, Mac Aogáin M, Chalmers JD, Elborn SJ Chotirmall SH. Geographic variation in the aetiology, epidemiology and microbiology of bronchiectasis. BMC Pulm Med. 2018;18(1):83 https://doi.org/10.1186/s12890-018-0638-0

4. Seitz AE, Olivier KN, Adjemian J, Holland SM, Prevots DR. Trends in bronchiectasis among medicare beneficiaries in the United States, 2000 to 2007. Chest. 2012;142(2):432-439. https://doi.org/10.1378/ chest.11-2209

5. Weycker D, Hansen GL, Seifer FD. Prevalence and incidence of noncystic fibrosis bronchiectasis among US adults in 2013. Chron Respir Dis. 2017;14(4):377-384. https://doi. org/10.1177/1479972317709649

6. Quint JK, Millett ER, Joshi M, Navaratnam V, Thomas SL, Hurst $J R$, et al. Changes in the incidence, prevalence and mortality of bronchiectasis in the UK from 2004 to 2013: a populationbased cohort study. Eur Respir J. 2016;47(1):186-93. https://doi. org/10.1183/13993003.01033-2015

7. Ringshausen FC, de Roux A, Diel R, Hohmann D, Welte T, Rademacher J. Bronchiectasis in Germany: a population-based estimation of disease prevalence. Eur Respir J. 2015;46(6):1805-7. https://doi.org/10.1183/13993003.00954-2015

8. Monteagudo M, Rodriguez-Blanco T, Barrecheguren M, Simonet $\mathrm{P}$ Miravitlles M. Prevalence and incidence of bronchiectasis in Catalonia, Spain: A population-based study. Respir Med. 2016;121:26-31. https://doi.org/10.1016/j.rmed.2016.10.014

9. Rezende Gonçalves J, Corso Pereira M, Figueiras Pedreira De Cerqueira EM, Oliveira Magro D, Mello Moreira M, Paschoal IA Severe obstructive disease: similarities and differences between smoker and non-smoker patients with COPD and/or bronchiectasis Rev Port Pneumol. 2013;19(1):13-8. https://doi.org/10.1016/j. rppneu.2012.05.003

10. Patel IS, Vlahos I, Wilkinson TM, Lloyd-Owen SJ, Donaldson GC, Wilks $M$, et al. Bronchiectasis, exacerbation indices, and inflammation in chronic obstructive pulmonary disease. Am J Respir Crit Care Med. 2004;170(4):400-7. https://doi.org/10.1164/ rccm.200305-6480C

11. O'Brien C, Guest PJ, Hill SL, Stockley RA. Physiological and radiological characterisation of patients diagnosed with chronic obstructive pulmonary disease in primary care. Thorax. 2000;55(8):635-42. https://doi.org/10.1136/thorax.55.8.635
12. Joish VN, Spilsbury-Cantalupo M, Operschall E, Luong B, Boklage $\mathrm{S}$. Economic burden of non-cystic fibrosis bronchiectasis in the first year after diagnosis from a US health plan perspective. Appl Health Econ Health Policy. 2013;11(3):299-304. https://doi.org/10.1007/ s40258-013-0027-z

13. de la Rosa D, Martínez-Garcia MA, Olveira C, Girón R, Máiz L, Prados C. Annual direct medical costs of bronchiectasis treatment: Impact of severity, exacerbations, chronic bronchial colonization and chronic obstructive pulmonary disease coexistence. Chron Respir Dis. 2016;13(4):361-371. https://doi.org/10.1177/1479972316643698

14. Amalakuhan B, Maselli DJ, Martinez-Garcia MA. Update in Bronchiectasis 2014. Am J Respir Crit Care Med. 2015;192(10):115561. https://doi.org/10.1164/rccm.201505-0926UP

15. Polverino E, Goeminne PC, McDonnell MJ, Aliberti S, Marshall SE, Loebinger MR, et al. European Respiratory Society guidelines for the management of adult bronchiectasis. Eur Respir J. 2017;50(3). pii: 1700629. https://doi.org/10.1183/13993003.00629-2017

16. Athanazio RA, Silva Filho LVRF, Vergara AA, Ribeiro AF, Riedi $C A$ Procianoy EDFA, et al. Brazilian guidelines for the diagnosis and treatment of cystic fibrosis. J Bras Pneumol. 2017;43(3):219-245. https://doi.org/10.1590/s1806-37562017000000065

17. Loebinger MR, Wells AU, Hansell DM, Chinyanganya N, Devara A, Meister $M$, et al. Mortality in bronchiectasis: a long-term study assessing the factors influencing survival. Eur Respir J. 2009;34(4):843-9. https://doi.org/10.1183/09031936.00003709

18. ten Hacken $\mathrm{NH}$, Wijkstra PJ, Kerstjens HA. Treatment of bronchiectasis in adults. BMJ. 2007;335(7629):1089-93. https://doi. org/10.1136/bmj.39384.657118.80

19. King PT. The pathophysiology of bronchiectasis. Int J Chron Obstruct Pulmon Dis. 2009;4:411-9. https://doi.org/10.2147/COPD.S6133

20. Cole PJ. Inflammation: a two-edged sword-the model of bronchiectasis. Eur J Respir Dis Suppl. 1986;147:6-15.

21. Hogg JC, Chu F, Utokaparch S, Woods R, Elliott WM, Buzatu L, et al. The nature of small-airway obstruction in chronic obstructive pulmonary disease. N Engl J Med. 2004;350(26):2645-53. https://doi. org/10.1056/NEJMoa032158

22. Tiddens HA, Donaldson SH, Rosenfeld M, Paré PD. Cystic fibrosis lung disease starts in the small airways: can we treat it more effectively? Pediatr Pulmonol. 2010;45(2):107-17. https://doi. org/10.1002/ppul.21154

23. Wurzel DF, Mackay IM, Marchant JM, Wang CY, Yerkovich ST Upham JW, et al. Adenovirus species $C$ is associated with chronic suppurative lung diseases in children. Clin Infect Dis. 2014;59(1):3440. https://doi.org/10.1093/cid/ciu225

24. Becroft DM. Bronchiolitis obliterans, bronchiectasis, and other sequelae of adenovirus type 21 infection in young children. J Clin Pathol. 1971;24(1):72-82. https://doi.org/10.1136/jcp.24.1.72

25. Kaschula RO, Druker J, Kipps A. Late morphologic consequences of measles: a lethal and debilitating lung disease among the poor. Rev 
Infect Dis. 1983;5(3):395-404. https://doi.org/10.1093/clinids/5.3.395

26. Johnston ID, Anderson HR, Lambert HP, Patel S. Respiratory morbidity and lung function after whooping-cough. Lancet. 1983;2(8359):1104-8. https://doi.org/10.1016/S0140-6736(83)90626-8

27. Brasil. Ministério da Saúde [homepage on the Internet]. Brasília: o Ministério [cited 2019 Apr 1]. Tuberculose: o que é, causas, sintomas, tratamento, diagnóstico e prevenção [about 20 screens]. Available from: http://portalms.saude.gov.br/saude-de-a-z/tuberculose

28. Jordan TS, Spencer EM, Davies P. Tuberculosis, bronchiectasis and chronic airflow obstruction. Respirology. 2010;15(4):623-8. https:// doi.org/10.1111/j.1440-1843.2010.01749.x

29. OIm MA, Caldini EG, Mauad T. Diagnosis of primary ciliary dyskinesia. J Bras Pneumol. 2015;41(3):251-63. https://doi.org/10.1590/S180637132015000004447

30. Weibel ER, Sapoval B, Filoche M. Design of peripheral airways for efficient gas exchange. Respir Physiol Neurobiol. 2005;148(1-2):3-21. https://doi.org/10.1016/.resp.2005.03.005

31. Svartengren K, Philipson K, Svartengren M, Nerbrink O, Camner P. Clearance in smaller airways of inhaled 6-microm particles in subjects with immotile-cilia syndrome. Exp Lung Res. 1995;21(5):667-82. https://doi.org/10.3109/01902149509050835

32. Schwardt JD, Neufeld GR, Baumgardner JE, Scherer PW. Noninvasive recovery of acinar anatomic information from $\mathrm{CO} 2$ expirograms. Ann Biomed Eng. 1994;22(3):293-306. https://doi. org/10.1007/BF02368236

33. Reid LM. Reduction in bronchial subdivision in bronchiectasis. Thorax. 1950;5(3):233-47. https://doi.org/10.1136/thx.5.3.233

34. Kang EY, Miller RR, Muller NL. Bronchiectasis: comparison of preoperative thin-section CT and pathologic findings in resected specimens. Radiology. 1995;195(3):649-54. https://doi.org/10.1148/ radiology.195.3.7753989

35. Im JG, Kim SH, Chung MJ, Koo JM, Han MC. Lobular low attenuation of the lung parenchyma on $\mathrm{CT}$ : evaluation of forty-eight patients. J Comput Assist Tomogr. 1996;20(5):756-62. https://doi. org/10.1097/00004728-199609000-00013

36. Bueno J, Flors $L$. The role of imaging in the diagnosis of bronchiectasis: the key is in the distribution. Radiologia. 2018;60(1):39-48. https://doi. org/10.1016/j.rx.2017.06.009

37. Kwak $\mathrm{N}$, Lee $\mathrm{CH}$, Lee HJ, Kang YA, Lee JH, Han SK, et al. Nontuberculous mycobacterial lung disease: diagnosis based on computed tomography of the chest. Eur Radiol. 2016;26(12):44494456. https://doi.org/10.1007/s00330-016-4286-6

38. Kudoh S, Keicho N. Diffuse panbronchiolitis. Clin Chest Med. 2012;33(2):297-305. https://doi.org/10.1016/j.ccm.2012.02.005

39. Franquet T, Giménez A, Rosón N, Torrubia S, Sabaté JM, Pérez C. Aspiration diseases: findings, pitfalls, and differential diagnosis. Radiographics. 2000;20(3):673-85. https://doi.org/10.1148/ radiographics.20.3.g00ma01673

40. Olveira C, Padilla A, Martínez-García MA, de la Rosa D, Girón RM, Vendrell $\mathrm{M}$, et al. Etiology of Bronchiectasis in a Cohort of 2047 Patients. An Analysis of the Spanish Historical Bronchiectasis Registry. Arch Bronconeumol. 2017;53(7):366-374. https://doi. org/10.1016/j.arbres.2016.12.003

41. Lonni S, Chalmers JD, Goeminne PC, McDonnell MJ, Dimakou K, De Soyza A, et al. Etiology of Non-Cystic Fibrosis Bronchiectasis in Adults and Its Correlation to Disease Severity. Ann Am Thorac Soc. 2015;12(12):1764-70. https://doi.org/10.1513/AnnalsATS.201507$4720 \mathrm{C}$

42. Shoemark A, Ozerovitch L, Wilson R. Aetiology in adult patients with bronchiectasis. Respir Med. 2007;101(6):1163-70. https://doi. org/10.1016/j.rmed.2006.11.008

43. Athanazio R, Pereira MC, Gramblicka G, Cavalcanti-Lundgren F, de Figueiredo MF, Arancibia F, et al. Latin America validation of FACED score in patients with bronchiectasis: an analysis of six cohorts. BMC Pulm Med. 2017;17(1):73. https://doi.org/10.1186/s12890-017-0417-3

44. Cherniack NS, Carton RW. Factors associated with respiratory insufficiency in bronchiectasis. Am J Med. 1966;41(4):562-71. https://doi.org/10.1016/0002-9343(66)90218-X

45. Koulouris NG, Retsou S, Kosmas E, Dimakou K, Malagari K, Mantzikopoulos G, et al. Tidal expiratory flow limitation, dyspnoea and exercise capacity in patients with bilateral bronchiectasis. Eur Respir J. 2003;21(5):743-8. https://doi.org/10.1183/09031936.03.00 301103

46. Roberts HR, Wells AU, Milne DG, Rubens MB, Kolbe J, Cole PJ, et al. Airflow obstruction in bronchiectasis: correlation between computed tomography features and pulmonary function tests.
Thorax. 2000;55(3):198-204. https://doi.org/10.1136/thorax.55.3.198

47. Pasteur MC, Bilton D, Hill AT; British Thoracic Society Bronchiectasis non-CF Guideline Group. British Thoracic Society guideline for non-CF bronchiectasis. Thorax. 2010;65 Suppl 1:i1-58. https://doi. org/10.1136/thx.2010.136119

48. Lee AL, Hill CJ, Cecins N, Jenkins S, McDonald CF, Burge AT, et al. Minimal important difference in field walking tests in non-cystic fibrosis bronchiectasis following exercise training. Respir Med. 2014;108(9):1303-9. https://doi.org/10.1016/j.rmed.2014.07.006

49. de Camargo AA, Amaral TS, Rached SZ, Athanazio RA, Lanza FC, Sampaio LM, et al. Incremental shuttle walking test: a reproducible and valid test to evaluate exercise tolerance in adults with noncystic fibrosis bronchiectasis. Arch Phys Med Rehabil. 2014;95(5):892-9. https://doi.org/10.1016/j.apmr.2013.11.019

50. ATS Committee on Proficiency Standards for Clinical Pulmonary Function Laboratories. ATS statement: guidelines for the six-minute walk test. Am J Respir Crit Care Med. 2002;166(1):111-7. https://doi. org/10.1164/ajrccm.166.1.at1102

51. Lee AL, Button BM, Ellis S, Stirling R, Wilson JW, Holland AE, et al. Clinical determinants of the 6-Minute Walk Test in bronchiectasis. Respir Med. 2009;103(5):780-5. https://doi.org/10.1016/j. rmed.2008.11.005

52. Cartlidge MK, Smith MP, Bedi P, Donaldson S, Clarke A, Mantoani LC, et al. Validation of the Incremental Shuttle Walk Test as a Clinical End Point in Bronchiectasis. Chest. 2018;154(6):1321-1329. https:// doi.org/10.1016/j.chest.2018.09.019

53. McDonnell MJ, Aliberti S, Goeminne PC, Dimakou K, Zucchett SC, Davidson J, et al. Multidimensional severity assessment in bronchiectasis: an analysis of seven European cohorts. Thorax. 2016;71(12):1110-1118. https://doi.org/10.1136/ thoraxjn-2016-208481

54. Jarvis WR. The epidemiology of colonization. Infect Control Hosp Epidemiol. 1996;17(1):47-52. https://doi.org/10.2307/30142366

55. Finch S, McDonnell MJ, Abo-Leyah H, Aliberti S, Chalmers JD. A Comprehensive Analysis of the Impact of Pseudomonas aeruginosa Colonization on Prognosis in Adult Bronchiectasis. Ann Am Thorac Soc. 2015;12(11):1602-11. https://doi.org/10.1513/ AnnalsATS.201506-3330C

56. Martínez-Garcia MA, Soler-Cataluña JJ, Perpiña-Tordera M, RománSánchez P, Soriano J. Factors associated with lung function decline in adult patients with stable non-cystic fibrosis bronchiectasis. Chest. 2007;132(5):1565-72. https://doi.org/10.1378/chest.07-0490

57. Boyton RJ, Reynolds CJ, Quigley KJ, Altmann DM. Immune mechanisms and the impact of the disrupted lung microbiome in chronic bacterial lung infection and bronchiectasis. Clin Exp Immunol. 2013;171(2):117-23. https://doi.org/10.1111/cei.12003

58. Faner R, Sibila O, Agustí A, Bernasconi E, Chalmers JD, Huffnagle $\mathrm{GB}$, et al. The microbiome in respiratory medicine: current challenges and future perspectives. Eur Respir J. 2017;49(4). pii: 1602086 https://doi.org/10.1183/13993003.02086-2016

59. Chalmers JD, Goeminne P, Aliberti S, McDonnell MJ, Lonni $S$, Davidson J, et al. The bronchiectasis severity index. An international derivation and validation study. Am J Respir Crit Care Med. 2014;189(5):576-85. https://doi.org/10.1164/rccm.201309-15750C

60. Aliberti S, Lonni S, Dore S, McDonnell MJ, Goeminne PC, Dimakou $K$, et al. Clinical phenotypes in adult patients with bronchiectasis. Eur Respir J. 2016;47(4):1113-22. https://doi. org/10.1183/13993003.01899-2015

61. Metersky ML, Aksamit TR, Barker A, Choate R, Daley CL, Daniels $L A$, et al. The Prevalence and Significance of Staphylococcus aureus in Patients with Non-Cystic Fibrosis Bronchiectasis. Ann Am Thorac Soc. 2018;15(3):365-370. https://doi.org/10.1513/AnnalsATS.201706$4260 \mathrm{C}$

62. Cuthbertson L, Rogers GB, Walker AW, Oliver A, Hafiz T, Hoffman $L R$, et al. Time between collection and storage significantly influences bacterial sequence composition in sputum samples from cystic fibrosis respiratory infections. J Clin Microbiol. 2014;52(8):3011-6. https://doi.org/10.1128/JCM.00764-14

63. The UK Cystic Fibrosis Trust Microbiology Laboratory Standards Working Group. [updated 2010, cited 2019 Apr 1]. Laboratory Standards for Processing Microbiological Samples from People with Cystic Fibrosis [Adobe Acrobat document, 40p.]. Available from: https://www.cysticfibrosis.org.uk/ /media/documents/the-work-wedo/care/consensus-docs-with-new-address/laboratory-standards ash $x$ ? la=en

64. Aaron $S D$, Vandemheen $K L$, Ferris W, Fergusson $D$, Tullis $E$, 
Haase D, et al. Combination antibiotic susceptibility testing to treat exacerbations of cystic fibrosis associated with multiresistant bacteria: a randomised, double-blind, controlled clinical trial. Lancet. 2005;366(9484):463-71. https://doi.org/10.1016/S0140 6736(05)67060-2

65. Brodt AM, Stovold E, Zhang L. Inhaled antibiotics for stable noncystic fibrosis bronchiectasis: a systematic review. Eur Respir J. 2014;44(2):382-93. https://doi.org/10.1183/09031936.00018414

66. Wilson CB, Jones PW, O'Leary CJ, Hansell DM, Cole PJ, Wilson R Effect of sputum bacteriology on the quality of life of patients with bronchiectasis. Eur Respir J. 1997;10(8):1754-60. https://doi.org/10. 1183/09031936.97.10081754

67. O'Leary CJ, Wilson CB, Hansell DM, Cole PJ, Wilson R, Jones PW. Relationship between psychological well-being and lung health status in patients with bronchiectasis. Respir Med. 2002;96(9):68692. https://doi.org/10.1053/rmed.2002.1330

68. O'Donnell AE, Barker AF, llowite JS, Fick RB. Treatment of idiopathic bronchiectasis with aerosolized recombinant human DNase I. rhDNase Study Group. Chest. 1998;113(5):1329-34. https://doi. org/10.1378/chest.113.5.1329

69. Pasteur MC, Helliwell SM, Houghton SJ, Webb SC, Foweraker JE, Coulden RA, et al. An investigation into causative factors in patients with bronchiectasis. Am J Respir Crit Care Med. 2000;162(4 Pt 1):1277-84. https://doi.org/10.1164/ajrccm.162.4.9906120

70. Wilson CB, Jones PW, O'Leary CJ, Hansell DM, Dowling RB, Cole PJ, et al. Systemic markers of inflammation in stable bronchiectasis Eur Respir J. 1998;12(4):820-4. https://doi.org/10.1183/09031936.9 8.12040820

71. Coban H, Gungen AC. Is There a Correlation between New Scoring Systems and Systemic Inflammation in Stable Bronchiectasis? Can Respir J. 2017;2017:9874068. https://doi.org/10.1155/2017/9874068

72. Fuschillo S, De Felice A, Balzano G. Mucosal inflammation in idiopathic bronchiectasis: cellular and molecular mechanisms. Eur Respir J. 2008;31(2):396-406. https://doi.org/10.1183/09031936.00069007

73. Araujo D, Shteinberg M, Aliberti S, Goeminne PC, Hill AT, Fardon $\mathrm{TC}$, et al. The independent contribution of Pseudomonas aeruginosa infection to long-term clinical outcomes in bronchiectasis. Eur Respir J. 2018;51(2). pii: 1701953. https://doi.org/10.1183/13993003.01953 2017

74. Martínez-García MÁ, de Gracia J, Vendrell Relat M, Girón RM, Máiz Carro L, de la Rosa Carrillo D, et al. Multidimensional approach to non-cystic fibrosis bronchiectasis: the FACED score. Eur Respir J 2014;43(5):1357-67. https://doi.org/10.1183/09031936.00026313

75. Martinez-Garcia MA, Athanazio RA, Girón R, Máiz-Carro L, de la Rosa D, Olveira $C$, et al. Predicting high risk of exacerbations in bronchiectasis: the E-FACED score. Int J Chron Obstruct Pulmon Dis. 2017; 12:275-284. https://doi.org/10.2147/COPD.S121943

76. de la Rosa Carrillo D, Athanazio R, Girón Moreno RM, Máiz Carro L, Olveira C, de Gracia J, et al. The annual prognostic ability of FACED and E-FACED scores to predict mortality in patients with bronchiectasis. ERJ Open Res. 2018;4(1). pii: 00139-2017. https:// doi.org/10.1183/23120541.00139-2017

77. Agarwal R, Chakrabarti A, Shah A, Gupta D, Meis JF, Guleria R, et al. Allergic bronchopulmonary aspergillosis: review of literature and proposal of new diagnostic and classification criteria. Clin Exp Allergy. 2013;43(8):850-73. https://doi.org/10.1111/cea.12141

78. Patterson TF, Thompson GR 3rd, Denning DW, Fishman JA Hadley S, Herbrecht R, et al. Practice Guidelines for the Diagnosis and Management of Aspergillosis: 2016 Update by the Infectious Diseases Society of America. Clin Infect Dis. 2016;63(4):e1-e60

79. Ryu YJ, Koh WJ, Daley CL. Diagnosis and Treatment of Nontuberculous Mycobacterial Lung Disease: Clinicians Perspectives. Tuberc Respir Dis (Seoul). 2016;79(2):74-84. https:// doi.org/10.4046/trd.2016.79.2.74

80. Griffith DE, Aksamit T, Brown-Elliott BA, Catanzaro A, Daley C, Gordin F, et al. An official ATS/IDSA statement: diagnosis, treatment, and prevention of nontuberculous mycobacterial diseases. Am Respir Crit Care Med. 2007;175(4):367-416. https://doi.org/10.1164/ rccm.200604-571ST

81. Stoller JK, Aboussouan LS. A review of a1-antitrypsin deficiency. Am J Respir Crit Care Med. 2012;185(3):246-59. https://doi.org/10.1164/ rccm.201108-1428C

82. Rubbo B, Lucas JS. Clinical care for primary ciliary dyskinesia: current challenges and future directions. Eur Respir Rev. 2017;26(145). pii: 170023. https://doi.org/10.1183/16000617.0023-2017

83. Smyth AR, Bell SC, Bojcin S, Bryon M, Duff A, Flume P, et al.
European Cystic Fibrosis Society Standards of Care: Best Practice guidelines. J Cyst Fibros. 2014;13 Suppl 1:S23-42. https://doi. org/10.1016/j.jcf.2014.03.010

84. Yazdani R, Abolhassani H, Asgardoon M, Shaghaghi M, Modaresi M Azizi G, et al. Infectious and Noninfectious Pulmonary Complications in Patients With Primary Immunodeficiency Disorders. J Investig Allergol Clin Immunol. 2017;27(4):213-224. https://doi.org/10.18176/ jiaci.0166

85. Martínez-García MA, Máiz L, Olveira C, Girón RM, de la Rosa D, Blanco M, et al. Spanish Guidelines on Treatment of Bronchiectasis in Adults. Arch Bronconeumol. 2018;54(2):88-98. https://doi. org/10.1016/j.arbres.2017.07.016

86. Treggiari MM, Retsch-Bogart G, Mayer-Hamblett N, Khan U, Kulich $\mathrm{M}$, Kronmal R, et al. Comparative efficacy and safety of 4 randomized regimens to treat early Pseudomonas aeruginosa infection in children with cystic fibrosis. Arch Pediatr Adolesc Med. 2011;165(9):847-56. https://doi.org/10.1001/archpediatrics.2011.136

87. Ratjen F, Munck A, Kho P, Angyalosi G; ELITE Study Group. Treatment of early Pseudomonas aeruginosa infection in patients with cystic fibrosis: the ELITE trial. Thorax. 2010;65(4):286-91. https://doi.org/10.1136/thx.2009.121657

88. Vallières E, Tumelty K, Tunney MM, Hannah R, Hewitt O, Elborn JS, et al. Efficacy of Pseudomonas aeruginosa eradication regimens in bronchiectasis. Eur Respir J. 2017;49(4). pii: 1600851. https://doi org/10.1183/13993003.00851-2016

89. White L, Mirrani G, Grover M, Rollason J, Malin A, Suntharalingam $J$. Outcomes of Pseudomonas eradication therapy in patients with non-cystic fibrosis bronchiectasis. Respir Med. 2012;106(3):356-60. https://doi.org/10.1016/j.rmed.2011.11.018

90. Yang JW, Fan LC, Lu HW, Miao XY, Mao B, Xu JF. Efficacy and safety of long-term inhaled antibiotic for patients with noncystic fibrosis bronchiectasis: a meta-analysis. Clin Respir J. 2016;10(6):731-739. https://doi.org/10.1111/crj.12278

91. Nadig TR, Flume PA. Aerosolized Antibiotics for Patients with Bronchiectasis. Am J Respir Crit Care Med. 2016;193(7):808-10. https://doi.org/10.1164/rccm.201507-1449LE

92. Aksamit T, De Soyza A, Bandel TJ, Criollo M, Elborn JS, Operschal E, et al. RESPIRE 2: a phase III placebo-controlled randomised trial of ciprofloxacin dry powder for inhalation in non-cystic fibrosis bronchiectasis. Eur Respir J. 2018;51(1). pii: 1702053. https://doi org/10.1183/13993003.02053-2017

93. De Soyza A, Aksamit T, Bandel TJ, Criollo M, Elborn JS, Operschal $\mathrm{E}$, et al. RESPIRE 1: a phase III placebo-controlled randomised trial of ciprofloxacin dry powder for inhalation in non-cystic fibrosis bronchiectasis. Eur Respir J. 2018;51(1). pii: 1702052. https://doi. org/10.1183/13993003.02052-2017

94. Haworth CW, Froehlich J, O'Neal T, Davis A, Gonda I, O'Donnell A. Inhaled Liposomal Ciprofloxacin in Patients with Bronchiectasis and Chronic Pseudomonas Aeruginosa Infection: Results from Two Parallel Phase III Trials (ORBIT-3 and -4). Am J Respir Crit Care Med. 2017:195:A7604.15

95. Murray MP, Govan JR, Doherty CJ, Simpson AJ, Wilkinson TS Chalmers JD, et al. A randomized controlled trial of nebulized gentamicin in non-cystic fibrosis bronchiectasis. Am J Respir Crit Care Med. 2011;183(4):491-9. https://doi.org/10.1164/rccm.201005 07560C

96. Hill SL, Burnett D, Hewetson KA, Stockley RA. The response of patients with purulent bronchiectasis to antibiotics for four months. Q J Med. 1988;66(250):163-73.

97. Wong C, Jayaram L, Karalus N, Eaton T, Tong C, Hockey H, et al. Azithromycin for prevention of exacerbations in non-cystic fibrosis bronchiectasis (EMBRACE): a randomised, double-blind placebo-controlled trial. Lancet. 2012;380(9842):660-7. https://doi. org/10.1016/S0140-6736(12)60953-2

98. Altenburg J, de Graaff CS, Stienstra Y, Sloos JH, van Haren EH, Koppers RJ, et al. Effect of azithromycin maintenance treatment on infectious exacerbations among patients with non-cystic fibrosis bronchiectasis: the BAT randomized controlled trial. JAMA 2013;309(12):1251-9. https://doi.org/10.1001/jama.2013.1937

99. Serisier DJ, Martin ML, McGuckin MA, Lourie R, Chen AC, Brain $B$, et al. Effect of long-term, low-dose erythromycin on pulmonary exacerbations among patients with non-cystic fibrosis bronchiectasis the BLESS randomized controlled trial. JAMA. 2013;309(12):1260-7. https://doi.org/10.1001/jama.2013.2290

100. Wu Q, Shen W, Cheng H, Zhou X. Long-term macrolides for noncystic fibrosis bronchiectasis: a systematic review and meta-analysis. Respirology. 2014;19(3):321-9. https://doi.org/10.1111/resp.12233 
101. Kelly C, Chalmers JD, Crossingham I, Relph N, Felix LM, Evans DJ, et al. Macrolide antibiotics for bronchiectasis. Cochrane Database Syst Rev. 2018;3:CD012406. https://doi.org/10.1002/14651858. CD012406.pub2

102. Gao YH, Guan WJ, Xu G, Tang Y, Gao Y, Lin ZY, et al. Macrolide therapy in adults and children with non-cystic fibrosis bronchiectasis: a systematic review and meta-analysis. PLoS One. 2014;9(3):e90047. https://doi.org/10.1371/journal.pone.0090047

103. Fan LC, Lu HW, Wei P, Ji XB, Liang S, Xu JF. Effects of long-term use of macrolides in patients with non-cystic fibrosis bronchiectasis: a meta-analysis of randomized controlled trials. BMC Infect Dis. 2015;15:160. https://doi.org/10.1186/s12879-015-0872-5

104. Zhuo GY, He Q, Xiang-Lian L, Ya-Nan Y, Si-Te F. Prolonged treatment with macrolides in adult patients with non-cystic fibrosis bronchiectasis: meta-analysis of randomized controlled trials. Pulm Pharmacol Ther. 2014;29(1):80-8. https://doi.org/10.1016/1 pupt.2014.02.002

105. Shi ZL, Peng H, Hu XW, Hu JG. Effectiveness and safety of macrolides in bronchiectasis patients: a meta-analysis and systematic review. Pulm Pharmacol Ther. 2014;28(2):171-8. https:// doi.org/10.1016/j.pupt.2013.09.003

106. Renna M, Schaffner C, Brown K, Shang S, Tamayo MH, Hegyi K, et al. Azithromycin blocks autophagy and may predispose cystic fibrosis patients to mycobacterial infection. J Clin Invest. 2011;121(9):3554 63. https://doi.org/10.1172/JCl46095

107. Albert RK, Schuller JL; COPD Clinical Research Network. Macrolide antibiotics and the risk of cardiac arrhythmias. Am J Respir Crit Care Med. 2014;189(10):1173-80. https://doi.org/10.1164/rccm.201402$0385 \mathrm{Cl}$

108. Rao GA, Mann JR, Shoaibi A, Bennett CL, Nahhas G, Sutton SS, et al. Azithromycin and levofloxacin use and increased risk of cardiac arrhythmia and death. Ann Fam Med. 2014;12(2):121-7. https://doi. org/10.1370/afm.1601

109. Kapur N, Petsky HL, Bell S, Kolbe J, Chang AB. Inhaled corticosteroids for bronchiectasis. Cochrane Database Syst Rev. 2018;5:CD000996. https://doi.org/10.1002/14651858.CD000996. pub3

110. Nicotra MB. Bronchiectasis. Semin Respir Infect. 1994;9(1):31-40.

111. Franco F, Sheikh A, Greenstone M. Short acting beta-2 agonists for bronchiectasis. Cochrane Database Syst Rev. 2003(3):CD003572. https://doi.org/10.1002/14651858.CD003572

112. Sheikh A, Nolan D, Greenstone M. Long-acting beta-2-agonists for bronchiectasis. Cochrane Database Syst Rev. 2001(4):CD002155. https://doi.org/10.1002/14651858.CD002155

113. Martinez-García MA, Soler-Cataluña JJ, Catalán-Serra $P$, Román-Sánchez P, Tordera MP. Clinical efficacy and safety of budesonide-formoterol in non-cystic fibrosis bronchiectasis. Chest. 2012;141(2):461-468. https://doi.org/10.1378/chest.11-0180

114. Lasserson T, Holt K, Evans D, Greenstone M. Anticholinergic therapy for bronchiectasis. Cochrane Database Syst Rev. 2001(4):CD002163. https://doi.org/10.1002/14651858.CD002163

115. Flude LJ, Agent P, Bilton D. Chest physiotherapy techniques in bronchiectasis. Clin Chest Med. 2012;33(2):351-61. https://doi. org/10.1016/j.ccm.2012.02.009

116. Lee $A L$, Burge $A$, Holland AE. Airway clearance techniques for bronchiectasis. Cochrane Database Syst Rev. 2013(5):CD008351. https://doi.org/10.1002/14651858.CD008351.pub2

117. Lee AL, Burge AT, Holland AE. Positive expiratory pressure therapy versus other airway clearance techniques for bronchiectasis. Cochrane Database Syst Rev. 2017;9:CD011699. https://doi org/10.1002/14651858.CD011699.pub2

118. Chang AB, Bell SC, Torzillo PJ, King PT, Maguire GP, Byrnes CA, et al. Chronic suppurative lung disease and bronchiectasis in children and adults in Australia and New Zealand Thoracic Society of Australia and New Zealand guidelines. Med J Aust. 2015;202(1):21-3. https:// doi.org/10.5694/mja14.00287

119. Davis PB. Cystic fibrosis since 1938. Am J Respir Crit Care Med. 2006;173(5):475-82. https://doi.org/10.1164/rccm.200505-8400E

120. Lee AL, Hill CJ, McDonald CF, Holland AE. Pulmonary Rehabilitation in Individuals With Non-Cystic Fibrosis Bronchiectasis: A Systematic Review. Arch Phys Med Rehabil. 2017:98(4):774-782.e1. https://doi. org/10.1016/j.apmr.2016.05.017

121. Lee AL, Hill CJ, Cecins N, Jenkins S, McDonald CF, Burge AT, et al. The short and long term effects of exercise training in non-cystic fibrosis bronchiectasis-a randomised controlled trial. Respir Res. 2014;15:44. https://doi.org/10.1186/1465-9921-15-44
122. Amorim A, Gamboa F, Azevedo P. New advances in the therapy of non-cystic fibrosis bronchiectasis. Rev Port Pneumol. 2013;19(6):266-75. https://doi.org/10.1016/j.rppneu.2013.03.006

123. Snijders D, Calgaro S, Bertozzi I, Quartesan S, Kozuh I, Lunardi $F$, et al. Inhaled mucoactive drugs for treating non-cystic fibrosis bronchiectasis in children. Int $\mathrm{J}$ Immunopathol Pharmacol. 2013;26(2):529-34. https://doi.org/10.1177/039463201302600228

124. Kellett F, Redfern J, Niven RM. Evaluation of nebulised hypertonic saline $(7 \%)$ as an adjunct to physiotherapy in patients with stable bronchiectasis. Respir Med. 2005;99(1):27-31. https://doi org/10.1016/j.rmed.2004.05.006

125. Kellett F, Robert NM. Nebulised 7\% hypertonic saline improves lung function and quality of life in bronchiectasis. Respir Med. 2011;105(12):1831-5. https://doi.org/10.1016/j.rmed.2011.07.019

126. Nicolson $\mathrm{CH}$, Stirling RG, Borg BM, Button BM, Wilson JW Holland AE. The long term effect of inhaled hypertonic saline $6 \%$ in non-cystic fibrosis bronchiectasis. Respir Med. 2012;106(5):661-7. https://doi.org/10.1016/j.rmed.2011.12.021

127. Bilton D, Tino G, Barker AF, Chambers DC, De Soyza A, Dupont $L J$, et al. Inhaled mannitol for non-cystic fibrosis bronchiectasis: a randomised, controlled trial. Thorax. 2014;69(12):1073-9. https://doi. org/10.1136/thoraxjnl-2014-205587

128. Nair GB, llowite JS. Pharmacologic agents for mucus clearance in bronchiectasis. Clin Chest Med. 2012:33(2):363-70. https://doi. org/10.1016/j.ccm.2012.02.008

129. Wills PJ, Wodehouse T, Corkery K, Mallon K, Wilson R, Cole PJ. Short-term recombinant human DNase in bronchiectasis. Effect on clinical state and in vitro sputum transportability. Am J Respir Crit Care Med. 1996;154(2 Pt 1):413-7. https://doi.org/10.1164/ ajrccm.154.2.8756815

130. Gao YH, Guan WJ, Xu G, Lin ZY, Tang Y, Lin ZM, et al. The Role of viral infection in pulmonary exacerbations of bronchiectasis in adults: a prospective study. Chest. 2015;147(6):1635-1643. https:// doi.org/10.1378/chest.14-1961

131. Shrestha S, Foxman B, Dawid S, Aiello AE, Davis BM, Berus J, et al. Time and dose-dependent risk of pneumococcal pneumonia following influenza: a model for within-host interaction between influenza and Streptococcus pneumoniae. J R Soc Interface. 2013;10(86):20130233. https://doi.org/10.1098/rsif.2013.0233

132. Polverino E, Cilloniz C, Menendez R, Gabarrus A, Rosales-Mayor E Alcaraz $\mathrm{V}$, et al. Microbiology and outcomes of community acquired pneumonia in non cystic-fibrosis bronchiectasis patients. J Infect. 2015;71(1):28-36. https://doi.org/10.1016/j.jinf.2015.03.009

133. Lundgren F, Maranhão B, Martins R, Chatkin JM, Palmieri M, Rabahi $M F$, et al. Vaccination in the prevention of infectious respiratory diseases in adults. Rev Assoc Med Bras (1992). 2014;60(1):4-15 https://doi.org/10.1590/1806-9282.60.02.004

134. Sociedade Brasileira de Imunizações [homepage on the Internet]. São Paulo: a Sociedade [2019 Apr 1]. Pneumologia-Guia de Imunização SBIm/SBPT. 2018-2019. [Adobe Acrobat document, 34 p.]. Available from: https://sbim.org.br/images/files/guiapneumologia-sbim-2018-2019.pdf

135. Onen ZP, Gulbay BE, Sen E, Yildiz OA, Saryal S, Acican T, et al. Analysis of the factors related to mortality in patients with bronchiectasis. Respir Med. 2007:101(7):1390-7. https://doi. org/10.1016/j.rmed.2007.02.002

136. Global Initiative for Chronic Obstructive Lung Disease (GOLD) [homepage on the Internet]. Bethesda: GOLD [cited 2019 Apr 1] Global Strategy for the Diagnosis, Management, and Prevention of COPD - 2018 Report. [Adobe Acrobat document, 155p.]. Available from: http://www.goldcopd.org

137. Weill D, Benden C, Corris PA, Dark JH, Davis RD, Keshavjee S et al. A consensus document for the selection of lung transplant candidates: 2014--an update from the Pulmonary Transplantation Council of the International Society for Heart and Lung Transplantation. J Heart Lung Transplant. 2015;34(1):1-15. https:// doi.org/10.1016/j.healun.2014.06.014

138. Corris PA. Lung transplantation for cystic fibrosis and bronchiectasis Semin Respir Crit Care Med. 2013;34(3):297-304. https://doi. org/10.1055/s-0033-1348469

139. Mauchley DC, Daley CL, Iseman MD, Mitchell JD. Pulmonary resection and lung transplantation for bronchiectasis. Clin Chest Med. 2012;33(2):387-96. https://doi.org/10.1016/j.ccm.2012.04.001

140. Hayes D Jr, Meyer KC. Lung transplantation for advanced bronchiectasis. Semin Respir Crit Care Med. 2010;31(2):123-38. https://doi.org/10.1055/s-0030-1249109 
141. Camargo PC, Teixeira RH, Carraro RM, Campos SV, Afonso Junior JE, Costa AN, et al. Lung transplantation: overall approach regarding its major aspects. J Bras Pneumol. 2015;41(6):547-53 https://doi. org/10.1590/s1806-37562015000000100

142. Beirne PA, Banner NR, Khaghani A, Hodson ME, Yacoub MH. Lung transplantation for non-cystic fibrosis bronchiectasis: analysis of a 13-year experience. J Heart Lung Transplant. 2005;24(10):1530-5. https://doi.org/10.1016/j.healun.2004.12.114

143. Birch J, Sunny SS, Hester KLM, Parry G, Kate Gould F, Dark JH, et al. Outcomes of lung transplantation in adults with bronchiectasis. BMC Pulm Med. 2018;18(1):82. https://doi.org/10.1186/s12890-018 0634-4

144. Rademacher J, Ringshausen FC, Suhling H, Fuge J, Marsch G Warnecke G, et al. Lung transplantation for non-cystic fibrosis bronchiectasis. Respir Med. 2016;115:60-5. https://doi.org/10.1016/j. rmed.2016.04.007

145. Fan LC, Liang S, Lu HW, Fei K, Xu JF. Efficiency and safety of surgical intervention to patients with Non-Cystic Fibrosis bronchiectasis: a meta-analysis. Sci Rep. 2015;5:17382. https://doi. org/10.1038/srep17382

146. Weber A, Stammberger U, Inci I, Schmid RA, Dutly A, Weder W Thoracoscopic lobectomy for benign disease--a single centre study on 64 cases. Eur J Cardiothorac Surg. 2001;20(3):443-8. https://doi. org/10.1016/S1010-7940(01)00689-3

147. Mitchell JD, Yu JA, Bishop A, Weyant MJ, Pomerantz M. Thoracoscopic lobectomy and segmentectomy for infectious lung disease. Ann Thorac Surg. 2012;93(4):1033-9; discussion 1039-40. https://doi.org/10.1016/j.athoracsur.2012.01.012

148. Zhang P, Zhang F, Jiang S, Jiang G, Zhou X, Ding J, et al. Videoassisted thoracic surgery for bronchiectasis. Ann Thorac Surg. 2011;91(1):239-43. https://doi.org/10.1016//.athoracsur.2010.08.035

149. Gursoy S, Ozturk AA, Ucvet A, Erbaycu AE. Surgical management of bronchiectasis: the indications and outcomes. Surg Today. 2010;40(1):26-30. https://doi.org/10.1007/s00595-009-4013-x

150. Coutinho D, Fernandes P, Guerra M, Miranda J, Vouga L. Surgical treatment of bronchiectasis: A review of 20 years of experience. Rev Port Pneumol (2006). 2016;22(2):82-5. https://doi.org/10.1016/j. rppnen.2015.09.007

151. Vallilo CC, Terra RM, de Albuquerque AL, Suesada MM, Mariani AW, Salge JM, et al. Lung resection improves the quality of life of patients with symptomatic bronchiectasis. Ann Thorac Surg. 2014;98(3):1034 41. https://doi.org/10.1016/j.athoracsur.2014.04.049

152. Hiramatsu $M$, Shiraishi $Y$, Nakajima $Y$, Miyaoka E, Katsuragi $N$ Kita $\mathrm{H}$, et al. Risk factors that affect the surgical outcome in the management of focal bronchiectasis in a developed country. Ann Thorac Surg. 2012;93(1):245-50. https://doi.org/10.1016/1. athoracsur.2011.08.077

153. Hill AT, Haworth CS, Aliberti S, Barker A, Blasi F, Boersma W, et al. Pulmonary exacerbation in adults with bronchiectasis: a consensus definition for clinical research. Eur Respir J. 2017;49(6). pii: 1700051 https://doi.org/10.1183/13993003.00051-2017

154. Tunney MM, Einarsson GG, Wei L, Drain M, Klem ER, Cardwell $C$, et al. Lung microbiota and bacterial abundance in patients with bronchiectasis when clinically stable and during exacerbation. Am J Respir Crit Care Med. 2013;187(10):1118-26. https://doi.org/10.1164/ rccm.201210-19370C

155. de la Rosa Carrillo D, Navarro Rolon A, Girón Moreno RM Montull Veiga B, Olveira Fuster C, Padilla Galo A, et al. Cost of Hospitalizations due to Exacerbation in Patients with Non-Cystic Fibrosis Bronchiectasis. Respiration. 2018;96(5):406-416. https://doi. org/10.1159/000489935

156. Chalmers JD, Aliberti S, Filonenko A, Shteinberg M, Goeminne PC, Hill AT, et al. Characterization of the "Frequent Exacerbator Phenotype" in Bronchiectasis. Am J Respir Crit Care Med 2018;197(11):1410-1420. https://doi.org/10.1164/rccm.20171122020C

157. Hill AT, Pasteur M, Cornford C, Welham S, Bilton D. Primary care summary of the British Thoracic Society Guideline on the management of non-cystic fibrosis bronchiectasis. Prim Care Respir J. 2011;20(2):135-40. https://doi.org/10.4104/pcrj.2011.00007

158. Chawla K, Vishwanath S, Manu MK, Lazer B. Influence of pseudomonas aeruginosa on exacerbation in patients with bronchiectasis. J Glob Infect Dis. 2015;7(1):18-22. https://doi. org/10.4103/0974-777X.150885

159. Finklea JD, Khan G, Thomas S, Song J, Myers D, Arroliga AC. Predictors of mortality in hospitalized patients with acute exacerbation of bronchiectasis. Respir Med. 2010;104(6):816-21. https://doi.org/10.1016/j.rmed.2009.11.02

160. Brill SE, Patel AR, Singh R, Mackay AJ, Brown JS, Hurst JR. Lung function, symptoms and inflammation during exacerbations of noncystic fibrosis bronchiectasis: a prospective observational cohor study. Respir Res. 2015;16:16. https://doi.org/10.1186/s12931-0150167-9

161. Guan WJ, Gao YH, Xu G, Lin ZY, Tang Y, Li HM, et al. Inflammatory Responses, Spirometry, and Quality of Life in Subjects With Bronchiectasis Exacerbations. Respir Care. 2015;60(8):1180-9. https://doi.org/10.4187/respcare.04004

162. Murray MP, Turnbull K, Macquarrie S, Hill AT. Assessing response to treatment of exacerbations of bronchiectasis in adults. Eur Respir J. 2009;33(2):312-8. https://doi.org/10.1183/09031936.00122508

163. Ailiyaer $Y$, Wang XX, Zhang Y, Li C, Li T, Qi Q, et al. A Prospective Trial of Nebulized Amikacin in the Treatment of Bronchiectasis Exacerbation. Respiration. 2018;95(5):327-333. https://doi. org/10.1159/000486134

164. Bilton D, Henig N, Morrissey B, Gotfried M. Addition of inhaled tobramycin to ciprofloxacin for acute exacerbations of Pseudomonas aeruginosa infection in adult bronchiectasis. Chest. 2006;130(5):150310. https://doi.org/10.1378/chest.130.5.1503 